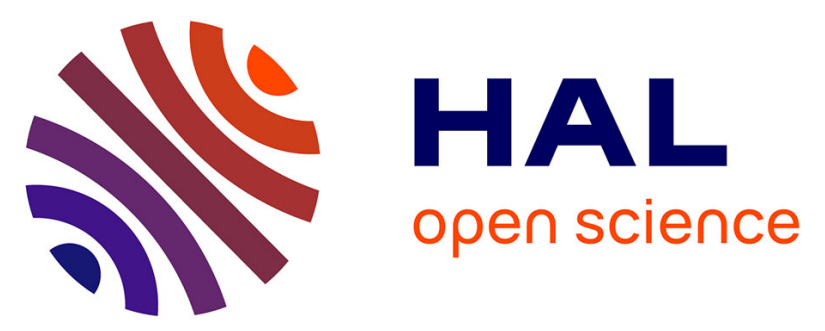

\title{
Tetracycline removal with activated carbons produced by hydrothermal carbonisation of Agave americana fibres and mimosa tannin
}

Taher Selmi, Angela Sanchez-Sanchez, Philippe Gadonneix, Jacek Jagiello, Mongi Seffen, Habib Sammouda, Alain Celzard, Vanessa Fierro

\section{To cite this version:}

Taher Selmi, Angela Sanchez-Sanchez, Philippe Gadonneix, Jacek Jagiello, Mongi Seffen, et al.. Tetracycline removal with activated carbons produced by hydrothermal carbonisation of Agave americana fibres and mimosa tannin. Industrial Crops and Products, 2018, 115, pp.146-157. 10.1016/j.indcrop.2018.02.005 . hal-03207566

\section{HAL Id: hal-03207566 \\ https://hal.univ-lorraine.fr/hal-03207566}

Submitted on 25 Apr 2021

HAL is a multi-disciplinary open access archive for the deposit and dissemination of scientific research documents, whether they are published or not. The documents may come from teaching and research institutions in France or abroad, or from public or private research centers.
L'archive ouverte pluridisciplinaire HAL, est destinée au dépôt et à la diffusion de documents scientifiques de niveau recherche, publiés ou non, émanant des établissements d'enseignement et de recherche français ou étrangers, des laboratoires publics ou privés. 


\section{Tetracycline removal with activated carbons produced by}

2 hydrothermal carbonisation of Agave americana fibres

\section{and mimosa tannin}

4

5 Taher Selmi ${ }^{\text {a }}$, Angela Sánchez-Sánchez ${ }^{\text {b }}$, Philippe Gadonneix ${ }^{\text {b }}$, Jacek Jagiello ${ }^{\mathrm{c}}$, Mongi Seffen ${ }^{\mathrm{a}}$, Habib Sammouda ${ }^{\mathrm{a}}$, Alain Celzard ${ }^{\mathrm{b}}$, Vanessa Fierro *

a. Laboratory of Energy and Materials (LabEM). High School of Sciences and Technology of Hammam Sousse, BP 4011Hammam Sousse (Sousse University-Tunisia).

b. Institut Jean Lamour, UMR Université de Lorraine-CNRS 7198, 27 rue Philippe Séguin, BP 21042, 88051 Epinal Cedex 9, France

c. Micromeritics Instrument Corporation, 4356 Communications Drive, Norcross, GA 30093, United States

* Corresponding author: (Vanessa Fierro) 


\section{Abstract}

Two series of carbons were prepared from Agave americana fibres (A) mixed with activation, Activated carbon, Tetracycline adsorption

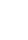

(1)
mimosa Tannin $(\mathrm{T})$ at different $\mathrm{T}$ to A weight ratios $W=0 / 4 ; 1 / 3 ; 2 / 2 ; 3 / 1$ and $4 / 0$. The first series, CTAW, was produced by direct pyrolysis of the precursors ( $\mathrm{T}, \mathrm{A}$, or blends) and the second one, CHTAW, was produced in two steps, hydrothermal carbonisation (HTC) and then pyrolysis. Materials from the CHTAW series presented higher surface areas, H/C atomic ratios and carbon yields than those of the CTAW series. CHTA2/2 was next activated with $\mathrm{CO}_{2}$ during 1, 2 or $3 \mathrm{~h}$. The appropriate selection of the synthesis conditions allowed obtaining high-surface area activated carbons (ACs) with similar carbon yields and average pore diameters as non-activated, low-surface area, carbon materials. CHTA2/2 activated for $2 \mathrm{~h}$ was tested for tetracycline (TC) adsorption, and the equilibrium was reached much faster than for a reference commercial $\mathrm{AC}$ due to the presence of macropores and mesopores provided by carbonised A. TC adsorption was spontaneous, and adsorption kinetics was adequately fitted by a pseudo-second-order model. TC adsorption essentially depends on surface area, and the results reported herein are in the range of those reported in the open literature.

2 Keywords: Hydrothermal carbonisation, Agave americana, Mimosa tannin, Physical (1) 24 


\section{Introduction}

Activated carbons (ACs) are porous materials characterised by highly developed pore

3 texture, specific area and surface functionalities. ACs are produced from many different

4 precursors, biomass among them, the selection of which being mainly conditioned by availability and cost. Among biomass, coconut shells (Rodríguez-Estupiñan et al., 2013), algae (Altenor et al., 2012), rice straw (Fierro et al., 2010a; Schaefer et al., 2017), lignin (Fierro et al., 2007) or ramboutan (Nephelium lappaceum) skin (Njoku et al., 2014) can be mentioned but are just examples. Pore texture, surface area and amount of functional groups in ACs can be enhanced by physical activation in which the precursor is pyrolysed under inert gas, usually nitrogen at high temperature, at least $800^{\circ} \mathrm{C}$, and further exposed to an oxidising gas. The latter is usually steam or $\mathrm{CO}_{2}$, at temperatures within the range from 800 to $1000^{\circ} \mathrm{C}$ (Ghouma et al., 2015). Physical activation with $\mathrm{CO}_{2}$ allows obtaining ACs with high surface areas and amount of surface functionalities (Molina-Sabio and Rodríguez-Reinoso, 2004). Activation time and flow of oxidising gas are the main parameters influencing the final AC characteristics (Acosta et al., 2016), and these parameters are sometimes optimised by experimental design (Zhao et al., 2011). Unlike for chemical activation, the resultant ACs doesn't need washing, which is a time-consuming step.

In the last decade, the interest for hydrothermal carbonisation (HTC) treatment significantly increased (Braghiroli et al., 2014; Braghiroli et al., 2015; Schaefer et al., 2016), although this process is known since 1913 (Bergius, 1915). HTC indeed allows transforming biomass precursors into hydrochars with a hydrophilic shell and a hydrophobic core (Braghiroli et al., 2015) in a very simple way. In brief, biomass and water are introduced in an autoclave which is then placed in an oven at moderate temperature $\left(150-250^{\circ} \mathrm{C}\right)$, and in which

24 the pressure is auto-generated. In these conditions, hydrolysis of the soluble biopolymers takes place, followed by fragmentation (Braghiroli et al., 2015). Next, the resultant monomers 
1 condensate and the as-obtained nuclei grow through a diffusion process, usually leading to

2 carbonaceous microspheres. Different biomasses have been submitted to HTC to produce

3 carbon materials, such as corn stalk and Tamarix ramosissima (Ling-Ping et al., (2012) ),

4 cellulose (Luca et al., 2014) or tannin (Braghiroli et al., 2015). HTC is also an interesting

5 method for producing carbons doped with heteroatoms such as nitrogen. Thus, nitrogen-rich

6 carbonaceous materials were synthesised from tannin submitted to HTC in concentrated

7 ammonia (Braghiroli et al., 2012). However, hydrochars must be pyrolysed for obtaining true

8 carbon materials, and have to be further activated to enhance their porosity and functionalities

9 and hence to produce activated carbons (ACs).

ACs are widely used as adsorbents and are applied in many fields such as, among 11 others, air purification (Choi et al., 2016), drinking water and wastewater treatment (Zietzschmann et al., 2016 ), gas storage (Sethia and Sayari, 2016), or purification of 13 pharmaceutical products ( $\mathrm{Li}$ et al., 2015). The gradual increase of antibiotics presence in 14 natural water and antibiotics bioaccumulation, tetracycline (TC) among them, is a serious threat to the environment. Therefore, antibiotics removal is a scientific and technological challenge, and a matter of public concern. Antibiotics removal can be achieved by membrane filtration (Kovalova et al., 2012), electrochemical treatments (Dirany et al., 2012) or adsorption onto porous materials (Acosta et al., 2016; Ncibi and Mika, 2015).

The main objective of the present study was to remove TC using ACs produced from a low-cost, easily available and highly abundant local biomass in Tunisia: Agave americana

21 fibres (A). Mimosa tannin (T) was used to increase the carbon yield, and ACs were synthesised by varying several experimental conditions: T/A weight ratio, addition of an HTC 23 step or not, and activation time. We showed that the ACs prepared here had higher 24 performances than a commercial AC in terms of TC adsorption. Traditional studies including 25 basic thermodynamic calculations, $\mathrm{pH}$ effect, equilibrium and kinetics aspects were also 
1 carried out. A review of the TC adsorption capacities reported in the open literature was

2 finally provided in order to compare with the performances of the ACs prepared herein.

\section{Material and methods}

\subsection{Raw materials}

Agave americana fibres (A) were collected at Ben Salem, in the central Tunisian region of Kairouan. The relevant fibre extraction method was described in the literature (Ben Hamissa et al., 2007). Briefly, Agave americana plants were treated in a NaCl-salt solution at $80^{\circ} \mathrm{C}$ for $8 \mathrm{~h}$. Afterwards, they were beaten with a mallet and vigorously thrashed with a scraper in order to separate the fibres (Ben Hamissa et al., 2013). Fibres were washed several times with distilled water to remove non-cellulosic particles, and were dried in an oven at $70^{\circ} \mathrm{C}$ until constant weight. Then, the fibres were finely cut and sieved using an electric sifter. The particle size used in the experiments was comprised between 1 and $5 \mathrm{~mm}$.

Tannin (T) was extracted from Mimosa tree barks (Acacia mearnsii, De Wild), and was kindly supplied by the company SilvaChimica (San Michele Mondovi, Italy). This material is commercially available under the name "Fintan OP", and its extraction protocol has been described in detail elsewhere (Braghiroli et al., 2014). Briefly, fresh barks were subjected to leaching in a diluted sodium bisulphite aqueous solution at $70^{\circ} \mathrm{C}$. The resultant solutions were concentrated and then spray-dried to yield a light-brown powder containing $1 \mathrm{wt} \%$ of amino and imino acids, 4-6 wt. \% of water, 80-82 wt. \% of phenolic flavonoid materials. The remainder consists in monomeric and oligomeric carbohydrates, mainly broken pieces of hemicelluloses (Braghiroli et al., 2014).

4 A commercial AC, F300 provided by the company Calgon, was used as reference material for Tetracycline (TC) adsorption. TC, 98\% pure, was provided by Sigma Aldrich. 


\subsection{Activated carbon synthesis}

Two series of carbons were prepared from $4 \mathrm{~g}$ of different precursors obtained by mixing Agave americana fibre (A) and tannin (T) at several $\mathrm{T}$ to A weight ratios $(W)$ and maintaining the final mass to $4 \mathrm{~g}$ (i.e., $W=0 / 4 ; 1 / 3 ; 2 / 2 ; 3 / 1$ and $4 / 0$ ). The carbon precursors were labelled TA0/4; TA1/3; TA2/2; TA3/1 and TA4/0, respectively, and this series was called TAW.

The first carbon series was prepared by direct pyrolysis of the aforementioned TAW precursors in a horizontal tubular furnace (Carbolite CTF). 1g of carbon precursor was placed in a quartz boat and transferred into a quartz tube continuously flushed with nitrogen at a flow rate of $100 \mathrm{~mL} / \mathrm{min}$. The tube was heated in the furnace at $1{ }^{\circ} \mathrm{C} / \mathrm{min}$ up to $900^{\circ} \mathrm{C}$, and such final temperature was held for $1 \mathrm{~h}$. Then, the furnace was allowed to cool down to room temperature under nitrogen flow. The resultant samples after pyrolysis and drying at $105^{\circ} \mathrm{C}$ were labelled CTAW, where "C" means carbon.

The second carbon series was prepared by submitting the TAW precursors to hydrothermal carbonisation (HTC) before pyrolysis at $900^{\circ} \mathrm{C}$. In a typical experiment, $4 \mathrm{~g}$ of TAW were introduced in a glass vial containing $40 \mathrm{~g}$ of distilled water, and the vial was introduced into a $200 \mathrm{~mL}$ Teflon-lined autoclave (Anton Parr). The autoclave was then introduced for $6 \mathrm{~h}$ in a ventilated oven pre-heated at $180^{\circ} \mathrm{C}$. The choice of $\mathrm{HTC}$ conditions ensured total HTC conversion (Braghiroli et al., 2014).

After HTC and drying at $105^{\circ} \mathrm{C}$, the samples were labelled HTAW, where "H" means HTC, and they were pyrolysed in the same conditions as for the first series. The resultant samples were then labelled CHTAW, where C, H, T, A and W have the same meaning as before.

One of the carbon samples, CHTA2/2, was chosen for physical activation with $\mathrm{CO}_{2}$ in order to further develop its textural properties. $\mathrm{CO}_{2}$ activation was carried out in a horizontal tubular furnace. $1 \mathrm{~g}$ of CHTA2/2 was placed in a quartz boat and transferred into a quartz tube 
1 flushed with high-purity nitrogen at a flow rate $100 \mathrm{~mL} / \mathrm{min}$, then heated at $5^{\circ} \mathrm{C} / \mathrm{min}$ up to

$2900^{\circ} \mathrm{C}$. Once the final temperature was reached, $\mathrm{N}_{2}$ was replaced by $\mathrm{CO}_{2}$ at a flow rate of 60

$3 \mathrm{~mL} / \mathrm{min}$ during 1,2 or $3 \mathrm{~h}$. Next, the furnace was allowed to cool under nitrogen flowing at

$4100 \mathrm{~mL} / \mathrm{min}$. ACs were labelled act_CHTA2/2, where " $\mathrm{t}$ " stands for the activation time (h),

5 from 1 to 3h, i.e., ac1_CHTA2/2, ac2_CHTA2/2, ac3_CHTA2/2, respectively.

6 Carbon yield: $Y_{C}$, total carbon yield: $Y_{T, C}$, HTC yield: $Y_{H}$, HTC total yield: $Y_{T, H}$, carbon yield

7 after HTC: $Y_{C, H}$, and total carbon yield after HTC: $Y_{T, C H}$, were calculated according to 8 equations SI1, SI2, SI3, SI4, SI5, and SI6, respectively, in the supplementary information 9 (SI).

10 The activation yield, $Y_{a c}(\%)$, on dry basis, was calculated as:

$$
Y_{a c}(\%)=\left(\frac{a c t \_C H T A 2 / 2(g)}{C H T A 2 / 2(g)}\right)_{d b} \times 100 \quad \text { Equation } 1
$$

12 and the total yield of the process after HTC, pyrolysis and activation, $Y_{T, a c t} \mathrm{CH}(\%)$, as:

$$
Y_{T, a c t \_C H}(\%)=\frac{Y_{a c}(\%) \times Y_{T, C H}(\%)}{100}=\left(\frac{a c t_{-} C H T A 2 / 2(g)}{T A 2 / 2(g)}\right)_{d b} \times 100 \quad \text { Equation } 2
$$
The total yield, $Y_{T}$, is thus either $Y_{H}, Y_{T, C}, Y_{T, C H}$ or $Y_{T, a c t-C H}$ for the series HTAW, CTAW, CHTAW or act_CHTA2/2, respectively, depending on the process considered.

Theoretical yields of processes such as HTC $(\mathrm{H})$, direct pyrolysis $(\mathrm{C})$ or HTC + pyrolysis $(\mathrm{CH})$, for $W=1 / 3,2 / 2$ or $3 / 1$, were calculated by a linear expression taking into account the experimental yields of pure T or pure A submitted to the process considered, and the value of $W$. For instance, for a TA mixture at $W=1 / 3$ submitted to direct pyrolysis, one gets:

$$
Y_{C, t h}(1 / 3)=\frac{Y_{C, \exp }(T)+Y_{C, \exp }(A) \times 3}{4}
$$

Equation 3

where the subscripts "exp" and "th" stand for experimental and theoretical, respectively. 


\subsection{Materials characterisation}

Carbon, hydrogen, oxygen, nitrogen and sulphur contents were directly determined using a CHONS elemental analyser (vario EL Cube, Elementar, Germany).

The $\mathrm{pH}$ at which the net charge of the surface is zero, named $p H_{P Z C}$ (point of zero charge), is affected by the nature and the amount of functional groups existing at the surface of activated carbons. The $\mathrm{pH}_{P Z C}$ was determined by following the $\mathrm{pH}$ drift method (Khan and Sarwar, 2007). 11 aqueous solutions of $0.01 \mathrm{~mol} / \mathrm{L} \mathrm{NaNO}_{3}$ were prepared, having $\mathrm{pH}$ adjusted to values ranging from 2 and 12 by steps of one $\mathrm{pH}$ unit by using either $0.5 \mathrm{~mol} / \mathrm{L} \mathrm{NaOH}$ or $0.5 \mathrm{~mol} / \mathrm{L} \mathrm{HCl}$. $0.5 \mathrm{~g}$ of carbon was added to $25 \mathrm{~mL}$ of each solution and left for a $48 \mathrm{~h}$ equilibration. The final $\mathrm{pH}$ was measured and plotted against the initial $\mathrm{pH}$. The $\mathrm{pH}$ at which the curve crossed the $\mathrm{pH}_{\text {initial }}=\mathrm{pH}_{\text {final }}$ line was taken as the $p H_{P Z C}$. The initial $\mathrm{pH}$ of the carbons was also determined. For that purpose, $0.1 \mathrm{~g}$ of carbon was placed in $10 \mathrm{~mL}$ of distilled water and equilibrated during 24 hours. Then, the $\mathrm{pH}$ of the suspension was measured at room temperature using a pH-meter (Denisa et al., 2009).

The amount of proton-binding groups was also measured, and the total surface charge $Q$ $(\mathrm{mmol} / \mathrm{L})$ was calculated. From these quantities, the numbers of groups having $p K_{a}$ values in selected ranges could be calculated (Jagiello et al., 1995). For that purpose, 0.1g of activated carbon was suspended in $50 \mathrm{~mL}$ of $\mathrm{NaNO}_{3}$ solution $(0.01 \mathrm{~mol} / \mathrm{L})$ as the supporting electrolyte and was stirred overnight to equilibrate. The suspension was then titrated with $\mathrm{NaOH}(0.1$ mol/L) under $\mathrm{N}_{2}$ saturation (Jagiello, 1994) using an automatic titrator (905 Titrando, Metrohm commanded with tiamo ${ }^{\circledR}$ software V2.2).

The infrared spectra of the hydrochars were obtained by using a Fourier-Transform Infrared (FTIR) spectrometer (Perkin-Elmer Frontier equipped with Perkin-Elmer Spotlight 400 FTIR Microscope) in the wavenumber range $4000-600 \mathrm{~cm}^{-1}$. The experiments were done on powdered samples, without pelletizing. 
Secondary electrons were used for observing the topographic contrast of samples using

2 scanning electron microscopy (FET Quanta 600 FEG) under an accelerating voltage of $3 \mathrm{kV}$.

3 Textural properties of samples were determined from nitrogen adsorption-desorption

4 isotherms at $-196^{\circ} \mathrm{C}$ and $\mathrm{CO}_{2}$ adsorption at $0^{\circ} \mathrm{C}$, using a Micromeritics ASAP 2020 and a

5 Micromeritics ASAP 2420, respectively. The BET (Brunauer-Emmet-Teller) method was

6 used to determine the specific surface area $S_{B E T}\left(\mathrm{~m}^{2} / \mathrm{g}\right)$ (Brunauer et al., 1938). Particular

7 attention was paid to the $C$ parameter in the BET equation that provides information about the

8 interaction of the adsorbent surface and the adsorbate, and which has to be positive. $S_{B E T}$

9 strongly depends on the range of relative pressures $\left(P / P_{0}\right)$ chosen to fit the BET equation to

10 the nitrogen isotherm, and therefore it cannot be automatically applied between 0.05 and 0.25 .

11 We thus plotted $V_{N 2} \times\left(1-P / P_{0}\right)$, where $V_{N 2}$ is the adsorbed nitrogen volume at a given value

12 of $\mathrm{P} / \mathrm{P}_{0}$, as a function of $P / P_{0}$ and starting at $P / P_{0}=0.01$. The maximum $\mathrm{P} / \mathrm{P}_{0}$ to fit the BET

13 equation will be that where $V_{N 2} \times\left(1-P / P_{0}\right)$ reaches its maximum. The micropore volume,

$14 V_{D R . N 2}\left(\mathrm{~cm}^{3} / \mathrm{g}\right)$, was determined using Dubinin-Raduskevich method (Dubinin, 1989). The

15 total pore volume accessible by adsorption, $V_{0.97}\left(\mathrm{~cm}^{3} / \mathrm{g}\right)$, was measured at a relative nitrogen

pressure of 0.97 . The mesopore volume, $V_{\text {mes }}\left(\mathrm{cm}^{3} / \mathrm{g}\right)$, was assumed to be the difference $V_{0.97}-$

$V_{D R . N 2}$. All the data were treated using the MicroActive software from Micromeritics ${ }^{\circledR}$.

18 Finally, the pore size distribution (PSD) was determined by application of the non-local

19 density functional theory (NLDFT), combining both $\mathrm{N}_{2}$ and $\mathrm{CO}_{2}$ adsorption isotherms using

20 the SAIEUS ${ }^{\circledR}$ Software provided by Micromeritics (Jagiello et al., 2015). The PSD was then

21 used to calculate the surface area, $S_{N L D F T}$, and the micropore volume, $V_{\text {micNLDFT }}$. The average

22 pore diameter, $d_{p, a v}$, was calculated as:

$$
d_{p, a v}(n m)=4 \times \frac{V_{0.97}}{S_{B E T}} \times 10^{-6}
$$

Equation 4

Mesoporosity (down to $3 \mathrm{~nm}$ ) and macroporosity were assessed by mercury porosimetry 
$10.24 \mathrm{MPa})$ first, then at high pressure (0.24-414 MPa). The Washburn theory (Washburn,

2 1921) was used to determine the pore size from the pressure through Equation 5:

3

$$
d=-\frac{4 \sigma_{H g} \cos \theta}{P}
$$

Equation 5

where $d$ is the pore diameter, $P$ is the pressure $(\mathrm{MPa}), \sigma_{H g}$ is the surface tension of mercury $\left(485 \mathrm{~mJ} / \mathrm{m}^{2}\right.$ at $\left.20^{\circ} \mathrm{C}\right)$, and $\theta$ is the contact angle $\left(130^{\circ}\right)$.

\subsection{Tetracycline (TC) adsorption}

The study of TC adsorption was carried out with one AC, taking into account the total surface area $S_{T o t}$, introduced elsewhere (Fierro et al., 2010a) and calculated according to:

$$
S_{T o t}=S_{B E T}\left(\mathbf{m}^{2} / \mathbf{g}\right) \times Y_{T}(\mathbf{w t} . \%)
$$

Equation 6

TC adsorption isotherms were performed in batch experiments as follows: $0.05 \mathrm{~g}$ of $\mathrm{AC}$ adsorbent, with a rod-like form and grain size not exceeding $1 \mathrm{~mm}$, was added to $100 \mathrm{~mL}$ of TC solution with the desired TC concentration $(0.5-400 \mathrm{mg} / \mathrm{L})$. The initial $\mathrm{pH}$ was adjusted by adding a small amount of diluted $\mathrm{NaOH}$ solution $(0.1 \mathrm{~mol} / \mathrm{L})$ and using a $\mathrm{pH}$ meter. The suspensions of AC in TC solution were stirred magnetically. TC adsorption thermodynamics was obtained from experiments carried out at three temperatures: 25,35 and $50^{\circ} \mathrm{C}$, using a thermostatic bath regulated at $\pm 1^{\circ} \mathrm{C}$. After a given time, a sample of $4 \mathrm{~mL}$ was withdrawn, the residual TC concentration was always measurable and determined with a UV-Vis spectrophotometer (Perkin-Elmer Lambda 35) at a wavelength of $358 \mathrm{~nm}$. Once the absorbance was measured, the liquid sample was put back into the flask in order to maintain a constant liquid volume. The amount of adsorbed TC at equilibrium, $q_{e}(\mathrm{mg} / \mathrm{g})$, was calculated by:

$$
\boldsymbol{q}_{e}=\frac{\left(C_{0}-C_{e}\right) V}{m}
$$


1 where $C_{0}$ and $C_{e}(\mathrm{mg} / \mathrm{L})$ are the initial and equilibrium TC concentrations, respectively. $V(\mathrm{~L})$

2 is the volume of solution and $m(\mathrm{~g})$ is the AC mass used. TC adsorption kinetics was fitted

3 with pseudo-first-order (PFO) and pseudo-second-order (PSO) models.

\section{$4 \quad 2.4 .1$ Kinetics models}

The Pseudo-First-Order (PFO) model proposed by Lagergren (Lagergren, 1898) is

6 generally used to describe solute adsorption in liquid phase for a small interval of time. The

7 variation of the solute concentration with time reads:

$$
\frac{d q_{t}}{d t}=k_{1}\left(q_{e 1}-q_{t}\right)
$$

\section{Equation 8}

where $t$ is the time (min), $k_{l}\left(\mathrm{~min}^{-1}\right)$ is the rate constant of PFO sorption at equilibrium, and $q_{e l}$ and $q_{t}(\mathrm{mg} / \mathrm{g})$ represent the amounts of TC adsorbed at equilibrium and at time $t$, respectively. After integration, the following equation is obtained:

$$
q_{t}=q_{e, 1}\left(1-\exp \left(-k_{1} \cdot t\right)\right)
$$

Equation 9

The initial adsorption rate, $h_{l}(\mathrm{mg} /(\mathrm{g} . \mathrm{min}))$, is defined as:

$$
h_{1}=k_{1} q_{e, 1}
$$

Equation 10

The Pseudo-Second-Order (PSO) model, proposed by Ho and McKay (Ho and McKay, 1999), is used for larger time intervals than in the PFO model. The following equation describes the variation of the solute concentration with time by the PSO model:

$$
\frac{d q_{t}}{d t}=k_{2}\left(q_{e 2}-q_{t}\right)^{2}
$$

Equation 11

After integration the following expression is obtained:

$$
q_{t}=\frac{q_{e, 2}^{2} \cdot k_{2} \cdot t}{1+q_{e, 2} \cdot k_{2} \cdot t}
$$

where $t, q_{e, 2}$ and $q_{t}$ have the same meaning as in the previous model, and $k_{2}$ is the rate constant of PSO sorption at equilibrium $(\mathrm{g} /(\mathrm{mg} \cdot \mathrm{min}))$. Then, the initial adsorption rate, $h_{2}$ $(\mathrm{mg} /(\mathrm{g} \cdot \mathrm{min}))$, can be calculated as follows:

$$
h_{2}=k_{2} q_{e, 2}^{2}
$$




\subsubsection{Thermodynamic studies}

Free energy $\left(\Delta G^{\circ}\right)$, entropy $\left(\Delta S^{\circ}\right)$, and enthalpy $\left(\Delta H^{\circ}\right)$ were determined using TC adsorption at the three selected temperatures. $\Delta G^{\circ}$ was calculated for each temperature according to:

$$
\Delta G^{\circ}=-R T \ln K_{C}
$$

Equation 14

where $\mathrm{R}$ is the gas constant $(8.314 \mathrm{~J} /(\mathrm{mol} . \mathrm{K})), T$ is the absolute temperature $(\mathrm{K})$, and $K_{C}$ (dimensionless) is the apparent equilibrium constant defined according to:

$$
K_{C}=\frac{C_{a d, e}}{C_{e}}
$$

Equation 15

$C_{a d, e}(\mathrm{mg} / \mathrm{L})$ is the concentration of adsorbed TC at equilibrium and $C_{e}$ is the concentration of $\mathrm{TC}$ in the aqueous phase at equilibrium $(\mathrm{mg} / \mathrm{L})$, considering the plateau of each isotherm at each $\mathrm{pH}$ and temperature. Plotting $\Delta G^{\circ}$ as a function of $T$, a straight line can be obtained with $\Delta H^{\circ}$ as the intercept and $\Delta S^{\circ}$ as the slope:

$$
\Delta G^{\circ}=\Delta H^{\circ}-T \Delta S^{\circ}
$$

Equation 16

\section{Results and discussion}

\subsection{Materials characterisation}

\subsubsection{Yields and elemental composition}

Figure 1 shows the Van Krevelen diagrams for biomass precursors, $\mathrm{T}$ and $\mathrm{A}$, and for hydrochars (Figure 1a), as well as for carbon materials CTAW, CHTAW and act_CHTA2/2 series (Figure 1b). As Van Krevelen diagrams deal with atomic ratios, we calculated atomic percentages by considering $100 \mathrm{~g}$ of material and dividing the weight percentage of each element by its atomic weight. The atomic percentages were then calculated by dividing the number of atoms of a given element by the total number of atoms, considering $\mathrm{C}, \mathrm{H}, \mathrm{N}$ and $\mathrm{O}$. Table SI 1 shows the total yields and elemental compositions of the precursors and of the CTAW, HTAW, CHTAW and act_CHTA2/2 series. The carbon content of A and T was 
143.87 wt.\% (27.68 at.\%) and 55.29 wt.\% (34.88 at.\%), respectively. Tannin is a polyphenolic

2 oligomer, i.e., is of aromatic nature, and hence both oxygen and hydrogen contents were 3 lower than those of Agave fibres, the latter being mainly composed of cellulose and 4 hemicelluloses with a minor content of lignin (Ben Hamissa et al., 2013).
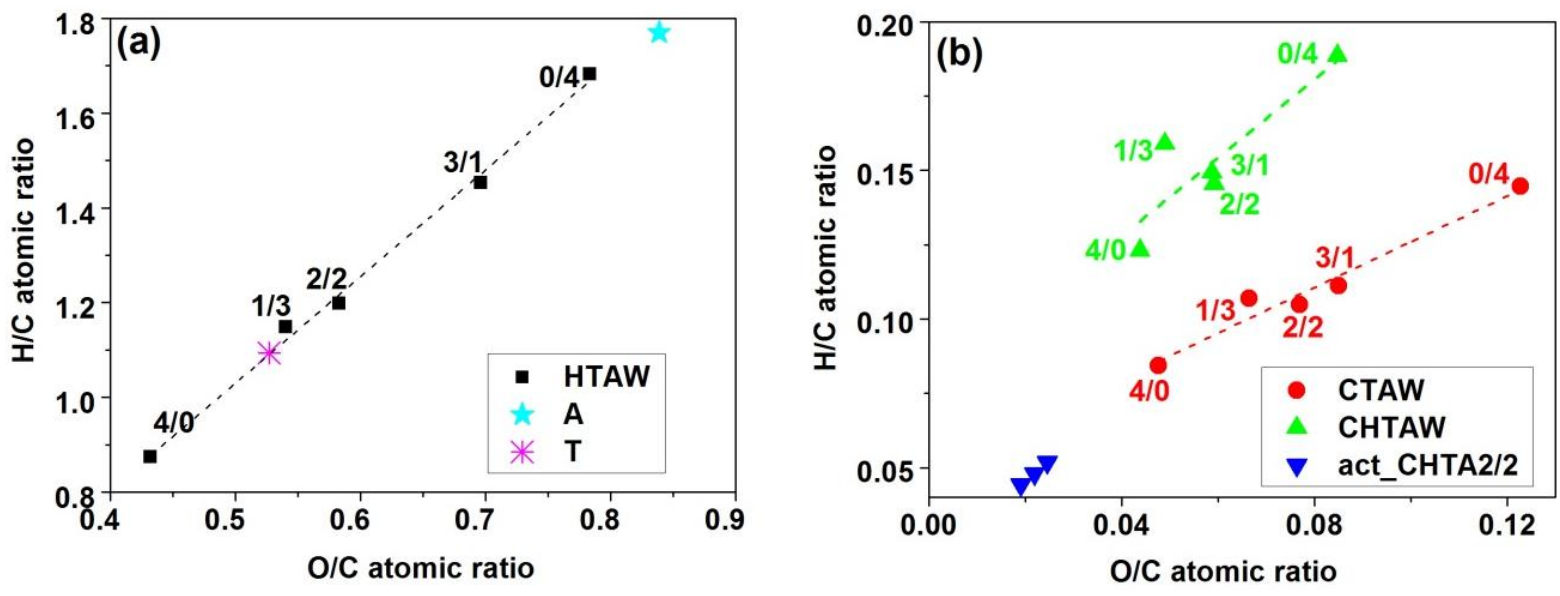

6 Figure 1: Van Krevelen diagrams of: (a) Agave, Tannin and HTAW series; and (b) CTAW, 7 CHTAW and act_CHTA2/2 series.

In agreement with these results, Agave had higher $\mathrm{H} / \mathrm{C}$ and $\mathrm{O} / \mathrm{C}$ atomic ratios than Tannin. After HTC, the carbon content slightly increased in the HTAW series and varied from 45.58 wt. $\%$ (28.75 at.\%) to 60.39 wt.\% (38.09 at.\%), corresponding to HTA0/4 (pure agave) and to HTA4/0 (pure tannin), respectively. A and T had the same nitrogen content, 0.22 wt. \% (0.12 at.\%), which did not vary appreciably after HTC. Increasing $W$ increased the carbon content and decreased both hydrogen and oxygen contents of the resultant hydrochars, leading to a remarkably straight line as seen in Figure 1a.

Figure $1 \mathrm{~b}$ shows that the $\mathrm{H} / \mathrm{C}$ and $\mathrm{O} / \mathrm{C}$ atomic ratios decreased after pyrolysis due to the evolution of volatiles mainly in the form of $\mathrm{H}_{2} \mathrm{O}, \mathrm{CO}_{2}$ and $\mathrm{CO}$ (Schaefer et al., 2016). For the same $\mathrm{O} / \mathrm{C}$ atomic ratio, the $\mathrm{H} / \mathrm{C}$ ratio was higher for CTAW than for the CHTAW series, probably indicating dehydration reaction during HTC and leading to lower hydrogen contents 
1 after pyrolysis. $\mathrm{H} / \mathrm{C}$ and $\mathrm{O} / \mathrm{C}$ atomic ratios decreased when increasing $W$ for the two series of

2 carbons. The nitrogen content was 0.28 wt. $\%$ (0.15 at.\%) and 0.52 wt. $\%$ (0.28 at.\%), on

3 average, for CHTAW and CTAW series, respectively (see Table SI 1). Therefore, when

4 biomass was directly pyrolysed, it maintained a lower content of heteroatoms (78.78 wt. \%

5 (49.70 at.\%) to 91.04 wt. \% (57.43 at.\%)) compared to carbons of the CHTAW series (87.83

6 wt. $\%(55.41$ at. $\%)$ - 94.58 wt. \% (59.67 at.\%)). $\mathrm{CO}_{2}$ activation of $\mathrm{CHTA} 2 / 2$ produced a

7 considerable reduction of both $\mathrm{H} / \mathrm{C}$ and $\mathrm{O} / \mathrm{C}$ atomic ratios as early as $1 \mathrm{~h}$ activation time, and

8 higher activation times further decreased those ratios. $\mathrm{H} / \mathrm{C}$ atomic ratios were between 0.05

9 and 0.04 for ac1_CHTA2/2 and ac3_CHTA2/2, respectively, while O/C atomic ratios were

10 around 0.02 .

11 Figure 2a shows the yields to hydrochars (HTAW series), carbons (CTAW and 12 CHTAW series) and activated carbons (act_CHTA2/2 series) from the initial TAW series. 13 The HTC yield of Tannin to hydrochar was lower, $58.2 \%$, than that of Agave, $63.3 \%$, but an 14 interesting finding is that mixing $\mathrm{A}$ with $\mathrm{T}$ and submitting the blend to HTC produced a 15 higher hydrochar yield with respect to the theoretical values calculated from the individual 16 hydrochar yields of $\mathrm{A}$ and T. Figure 2a indeed shows that the yield to hydrochar did not 17 change linearly when increasing $W$, meaning that the addition of a phenolic molecule to a 18 lignocellulosic material increased the hydrochar yield, in agreement with previous results. 19 Thus, some authors (Braghiroli, 2014; Brun et al., 2013; Ryu et al., 2010) showed that 20 phloroglucinol acts as a crosslinking agent, promoting sugar nucleation mechanism and 21 increasing the final HTC carbon yield by $20 \%$. 

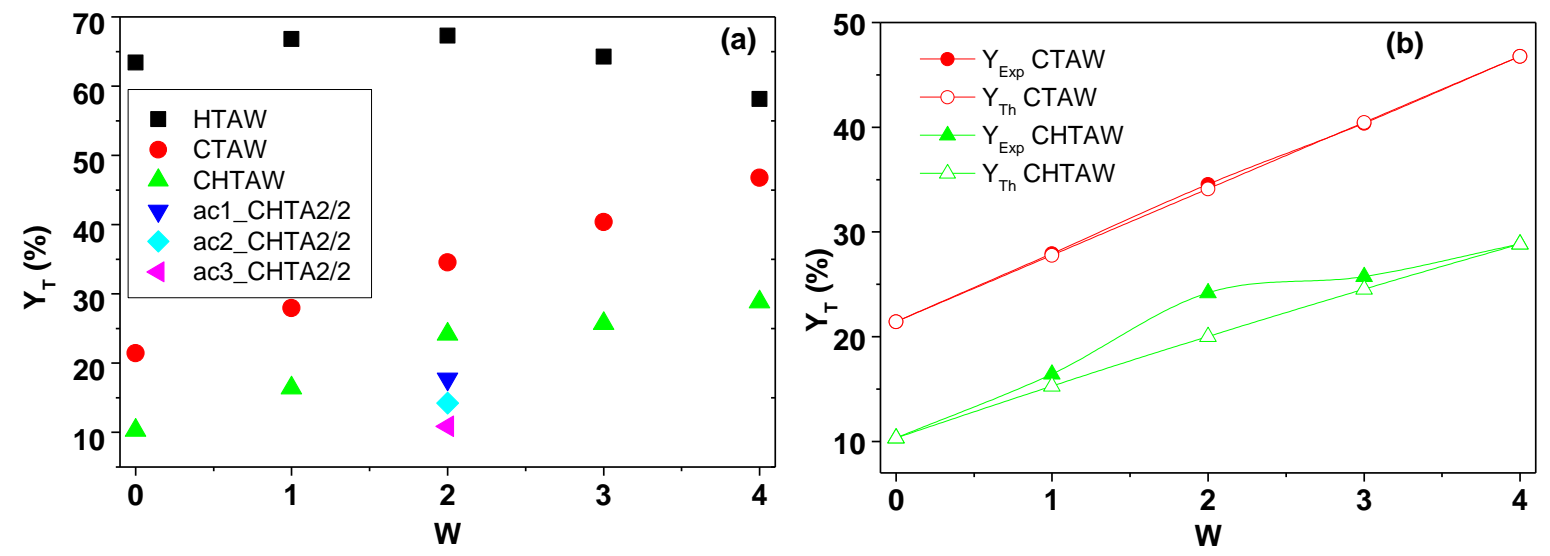

2 Figure 2 : (a) Total yield to hydrochar (HTAW), carbon (CHTAW and CTAW) or activated carbon (act_CHTA2/2); and (b) Experimental (full symbols) and theoretical (empty symbols)

4 carbon yield: CTAW and CHTAW as a function of $W$.

The highest difference was found when HTA2/2 was submitted to HTC. The theoretical yield was $60.78 \%$ whereas the experimental value was $67.29 \%$. This difference was maintained after pyrolysis. The yield to CTAW series varied from 21.43 to $46.77 \%$ and was

9 higher than that of CHTAW series, which ranged from 10.30 to $28.82 \%$. In both series, the 10 yield increased with $W$ due to the higher carbon yield of tannin. We could observe that there 11 was no linear increase of yield with $W$ for the CHTAW series, unlike what was seen for the 12 HTAW series. In order to better show this effect, Figure $2 b$ presents the theoretical and experimental carbon yields for both CTAW and CHTAW series. For direct pyrolysis, the experimental and theoretical yields were equal, but important differences were observed when materials were submitted together to HTC beforehand, especially at $W=2 / 2$.

\subsubsection{Textural properties}

Figure 3 shows the adsorption-desorption isotherms of $\mathrm{N}_{2}$ at $-196^{\circ} \mathrm{C}$ for series CTAW, CHTAW and act_CHTA2/2. The $\mathrm{CO}_{2}$ adsorption isotherms for the same materials are given as supplementary information (Figure SI 1). 
All materials presented a steep increase in the $\mathrm{N}_{2}$ volume adsorbed at very low relative

2 pressure $\left(P / P_{0}<0.01\right)$, indicating the existence of narrow micropores (Szczurek et al., 2011).

3 According to the IUPAC classification, the CTAW samples exhibit $\mathrm{N}_{2}$ adsorption isotherms

4 of type Ia (Thommes et al., 2015), characteristic of microporous materials with narrow

5 micropores. A nearly horizontal plateau, above $P / P_{0}=0.1$, was observed together with the

6 presence of mesopores, indicated by the small hysteresis loop closing at $P / P_{0}=0.2$.

7 Increasing the amount of Tannin, i.e., increasing $W$ from 0 at 4 , produced a higher micropore

8 volume, from $0.12 \mathrm{~cm}^{3} / \mathrm{g}$ to $0.21 \mathrm{~cm}^{3} / \mathrm{g}$, and a higher $S_{B E T}$ from $321 \mathrm{~m}^{2} / \mathrm{g}$ to $546 \mathrm{~m}^{2} / \mathrm{g}$ (see

9 Table SI 2), indicating the development of the porosity. This result was confirmed by the

10 isotherms of $\mathrm{CO}_{2}$ of Figure SI 1, and the corresponding pore texture parameters are gathered

11 in Table SI 2.

CHTAW and act_CHTA2/2 exhibited $\mathrm{N}_{2}$ adsorption isotherms of type Ib (Thommes et al., 2015), characteristic of developed pore texture with a wider supermicroporosity than before and the existence of pores between 0.7 and $2 \mathrm{~nm}$ wherein cooperative filling is possible. For the CHTAW series, we observed an increase of the amount of adsorbed nitrogen in the micropores, from 0.15 to $0.26 \mathrm{~cm}^{3} / \mathrm{g}$, and an increase of $S_{B E T}$ from 406 to $683 \mathrm{~m}^{2} / \mathrm{g}$, with the addition of Tannin at a weight ratio $W=1 / 3$. A further increase of $W$ reduced the mesopore volume, but the micropore volume and $S_{B E T}$ remained essentially unchanged. Comparing the pore texture parameters of CTAW and CHTAW (Figure 3a and Figure 3c), we can conclude that a preliminary hydrothermal step allowed an enhanced development of the microporosity during pyrolysis, which produced higher surface areas. The PSD calculated by the NLDFT model were not very different for CTAW and CHTAW series, since the micropore volume generally controls the value of $S_{B E T}$.

The sample CHTA2/2, having the highest yield increase when compared to the theoretical one, was chosen to further develop its textural properties by $\mathrm{CO}_{2}$ activation. Figure 
$13 \mathrm{e}$ shows the $\mathrm{N}_{2}$ adsorption-desorption isotherms of CHTA2/2 after activation at 1, 2 and 3

2 hours, compared to those of the non-activated sample. The micropore volume increased with

3 the activation time from 0.25 to $0.48 \mathrm{~cm}^{3} / \mathrm{g}$, and the shoulder of the isotherm widened,

4 showing an increase of the amount of wider micropores. At $P / P_{0}>0.1$, a plateau was not

5 reached and the slope of the curve increased with the activation time, suggesting a progressive

6 development of the porosity as shown by the PSDs in Figure 3f. The micropore volume,

$7 \quad V_{D R, N 2}$ determined by DR method applied to $\mathrm{N}_{2}$ isotherm, was lower than the one determined

8 by $\mathrm{CO}_{2}$ isotherm, $V_{D R . C O 2}: 0.25$ and $0.29 \mathrm{~cm}^{3} / \mathrm{g}$, respectively, for CHTA2/2. The difference

9 between $V_{D R, N 2}$ and $V_{D R . C O 2}$ increased for ac1_CHTA2/2, meaning that CHTA2/2 had an

10 important fraction of narrow microporosity, i.e., inaccessible to $\mathrm{N}_{2}$ at $-196^{\circ} \mathrm{C}$, and the material

11 obtained after $1 \mathrm{~h}$ activation developed a microporosity even narrower (Braghiroli et al., 12 2017). After $2 \mathrm{~h}$ activation, $V_{D R, N 2}$ was higher than $V_{D R . C O 2}$, meaning a widening of the 13 microporosity. All the carbon materials prepared, activated or not, had $S_{N L D F T}$ higher than $14 S_{B E T}$, indicating the existence of narrow pores wherein only a monolayer of nitrogen between 15 two pore walls can be adsorbed (Braghiroli et al., 2017). Increasing the activation time from 1 16 to 3 hours made the specific surface area $S_{B E T}$ increase from 621 to $1250 \mathrm{~m}^{2} / \mathrm{g}$, and so did the 17 surface area determined by the NLDFT method, $S_{N L D F T}$, which varied from 934 to $1431 \mathrm{~m}^{2} / \mathrm{g}$ 18 (Table SI 2). The PSDs of the non-activated sample, CHTA2/2, and of the series 19 act_CHTA2/2, obtained by application of the NLDFT model to both $\mathrm{N}_{2}$ and $\mathrm{CO}_{2}$ isotherms, 20 are shown in Figure 3f. 

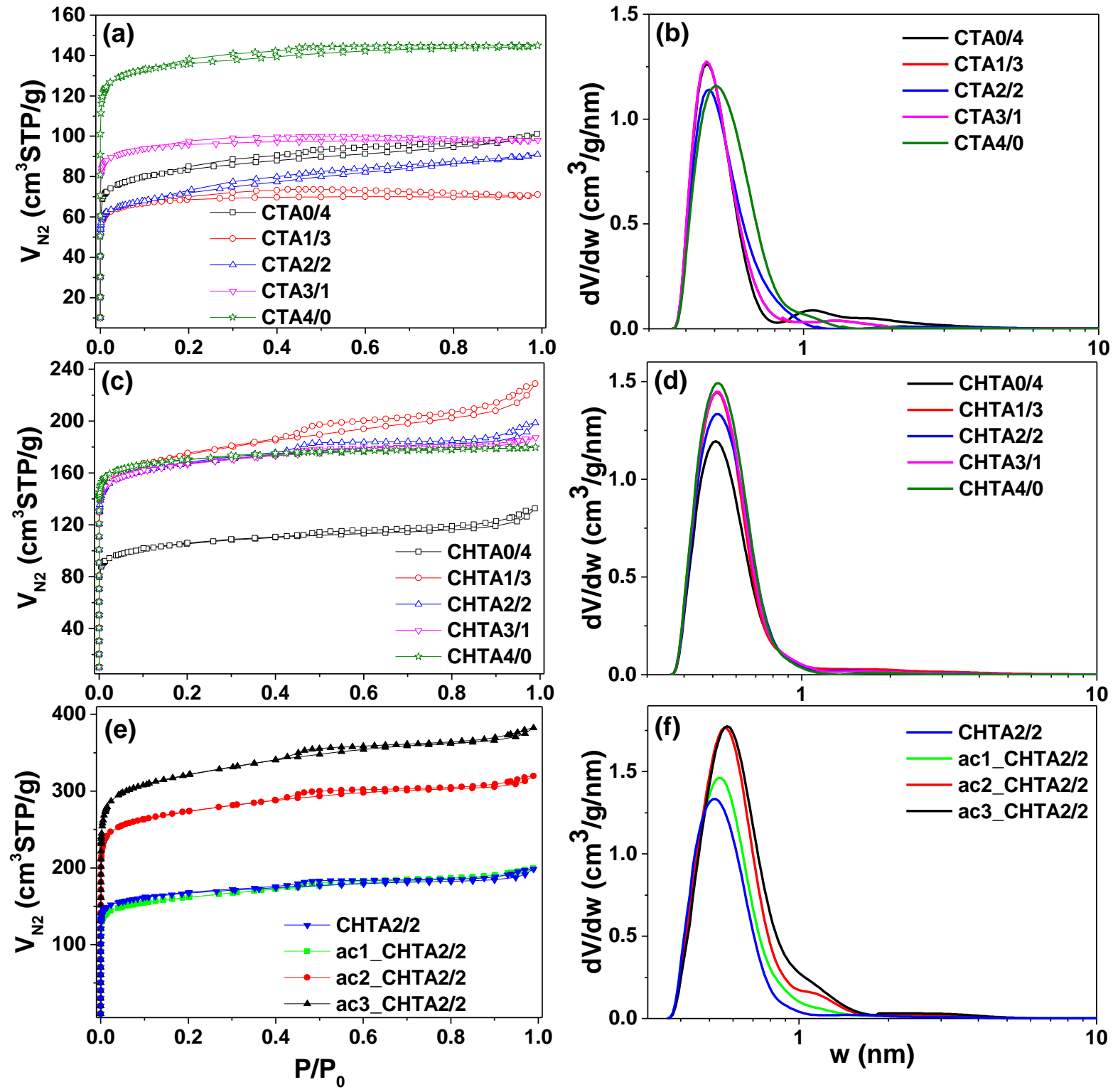

Figure 3: (a, c, e) $\mathrm{N}_{2}$ adsorption-desorption isotherms at $-196^{\circ} \mathrm{C}$; and $(\mathrm{b}, \mathrm{d}, \mathrm{f})$ corresponding PSDs.

Figure $4 \mathrm{a}$ and $4 \mathrm{~b}$ show the changes of $V_{0.97}$ and $S_{B E T}$ as a function of the total yield of

6 the process for synthesising the considered materials, $Y_{T}$. First, we can observe that $V_{0.97}$ and

$7 S_{B E T}$ followed similar trends due to the fact that most of the pore volume in all the materials

8 was mainly constituted of micropores $(<2 \mathrm{~nm})$, and the value of $S_{B E T}$ is essentially due to

9 microporosity. 

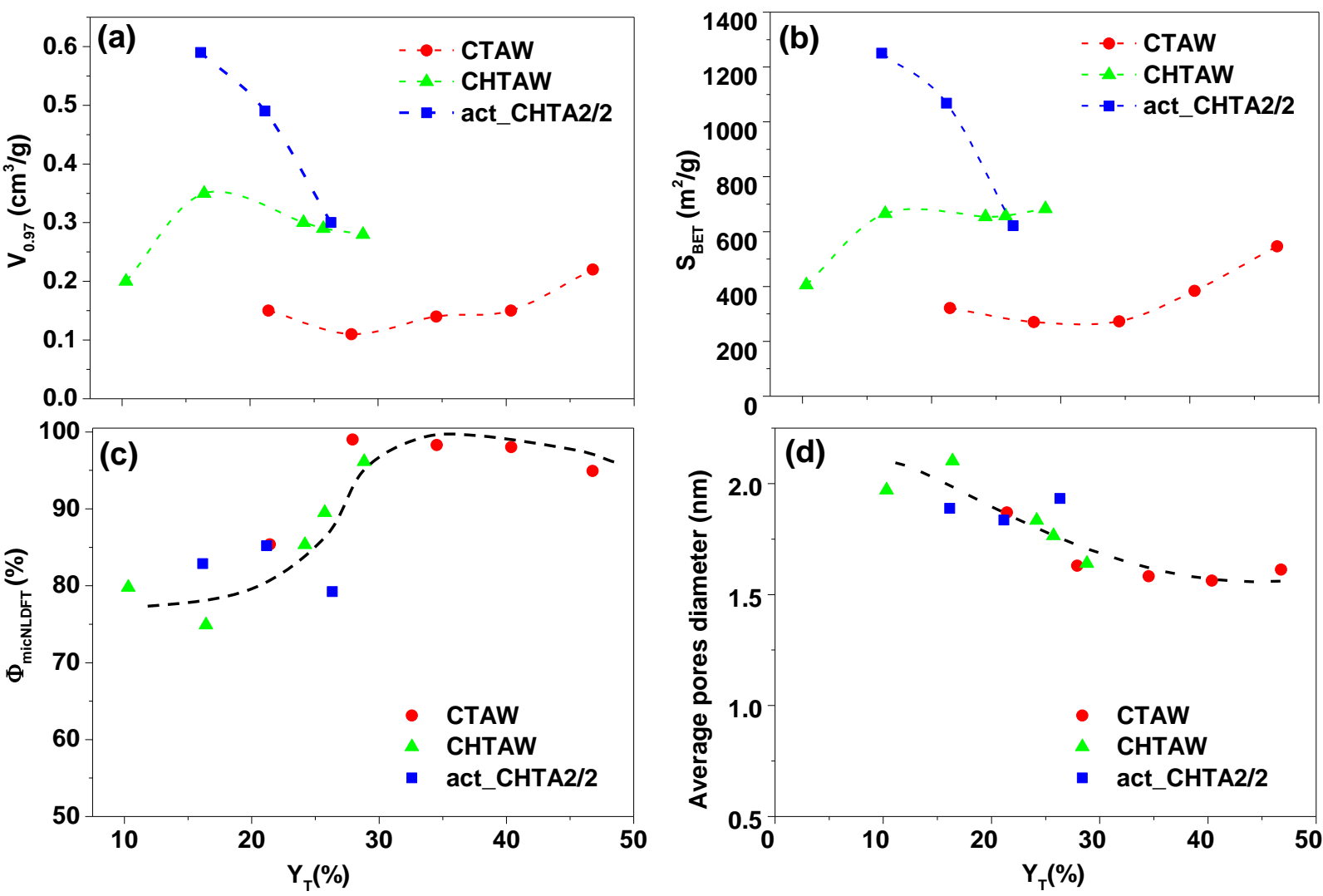

2 Figure 4: Correlation between total yields, $Y_{T}$, and: (a) total pore volume, $V_{0.97}$; (b) specific

3 surface area, $S_{B E T}$; (c) $\%$ of micropore volume from NLDFT, $\Phi_{m i c, N L D F T}(\%)$; and (d) average

4 pore diameter of CTAW, CHTAW and act_CHTA2/2 series.

Figure $4 \mathrm{c}$ shows the percentage of microporosity calculated by the NLDFT model, $\Phi_{m i c, N L D F T}(\%)=V_{m i c N L D F T} / V_{0.97}$. The highest $\Phi_{m i c, N L D F T}$ was found for materials submitted to

8 direct pyrolysis, especially when Tannin was present in the blend. Agave provided macro- and 9 mesoporosity to all materials, as confirmed by SEM observations (see below), but all materials were essentially microporous, with $\Phi_{m i c, N L D F T}$ higher than $75 \%$. This fact can be also

11 observed in Figure 4d when representing the average pore diameter, $d_{p, a v}$, as a function of $Y_{T}$.

12 As a general trend, $d_{p, a v}$ decreased when $Y_{T}$ increased, but ACs produced from CHTA2/2 had

13 similar values of $d_{p, a v}$ as those of some materials of the CHTAW series. However, these ACs

14 had much higher surface areas due to activation. Therefore, the appropriate selection of the 
1 synthesis conditions allowed obtaining activated carbons with high surface area but with

2 similar carbon yields and average pore diameters as those of non-activated, low-surface area,

3 carbon materials.

Figure 5a shows mercury intrusion curves for the act_CHTA2/2 series. At low pressure $(0.003 \mathrm{MPa})$ the mercury surrounds particles but does not enter the pores, whereas it penetrates into all pores wider than $3 \mathrm{~nm}$ when increasing progressively the pressure up to 400

$7 \mathrm{MPa}$.
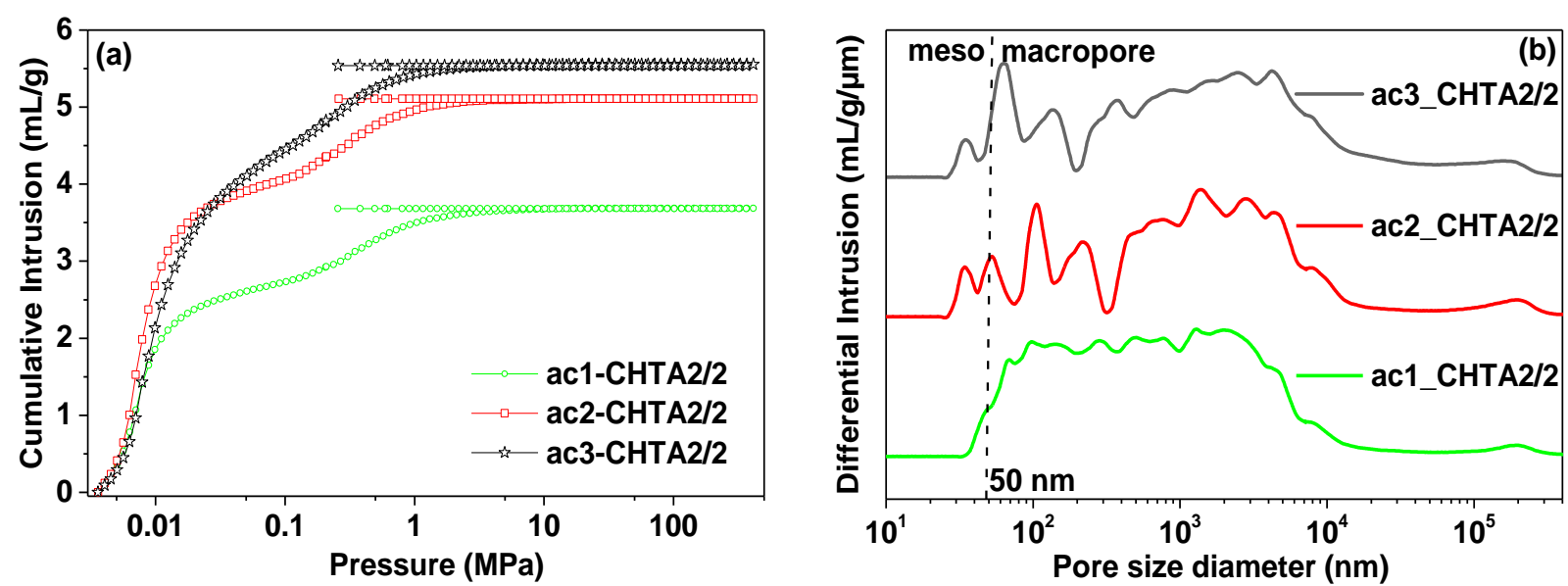

Figure 5: (a) Cumulative intrusion/extrusion of mercury; and (b) corresponding pore size distributions of the act_CHTA2/2 series.

The total volume penetrated by mercury increased from 3.69 to $5.55 \mathrm{~cm}^{3} / \mathrm{g}$ when the activation time increased from 1 to 3 hours (see Table SI 3). Figure 5b shows the PSDs calculated by applying Washburn's equation (Equation 5) to the data of Figure 5a. The PSDs become broader when increasing the activation time, although only little difference was noticed between ac2_CHTA2/2 and ac3_CHTA2/2.

Figure 6 shows the results of the potentiometric titration for the hydrochar HTA2/2, and its pyrolysed and activated derivatives: CHTA2/2 and act_CHTA2/2 series, respectively. Pyrolysis after HTC decreased the density of functional groups from 8.15 to $1.16 \mathrm{mmol} / \mathrm{g}$ (see 
1 Table 1), in good agreement with the decrease of $\mathrm{O}$ and $\mathrm{H}$ contents observed by elemental

2 analysis. The nature of the functional groups also changed. The increase of the activation time

3 progressively increased the amount of functional groups: $0.43,0.89$ and $4.92 \mathrm{mmol} / \mathrm{g}$ for

4 ac1_CHTA2/2, ac2_CHTA2/2 and ac3_CHTA2/2, respectively. The number of peaks,

5 representing different types of functional groups, were 3 and 4 for ac1_CHTA2/2 and

6 ac3_CHTA2/2, respectively, and the most acidic sites $(3<p K a<5)$ progressively vanished

7 when the activation time increased. However, the AC prepared with $2 \mathrm{~h}$ activation time,

8 ac2_CHTA2/2, still presented 5 types of functional groups, with 2 acidic ones centred at $p K a$

$9=3.97$ and 5.24. Upon increasing the activation time to $3 \mathrm{~h}$, the groups at $p K_{a}=3.97$

10 disappeared. The $p K_{a}$ distributions showed the predominance of strongly basic species such as

11 lactol- or hydroxyl-containing functional groups with $p K_{a}>8$ (Seredych et al., 2016). The

12 basicity of ACs was confirmed by the high value of $p H_{\text {initial }}$ and $p H_{P Z C}$, around 10 (Table 1).

13

14
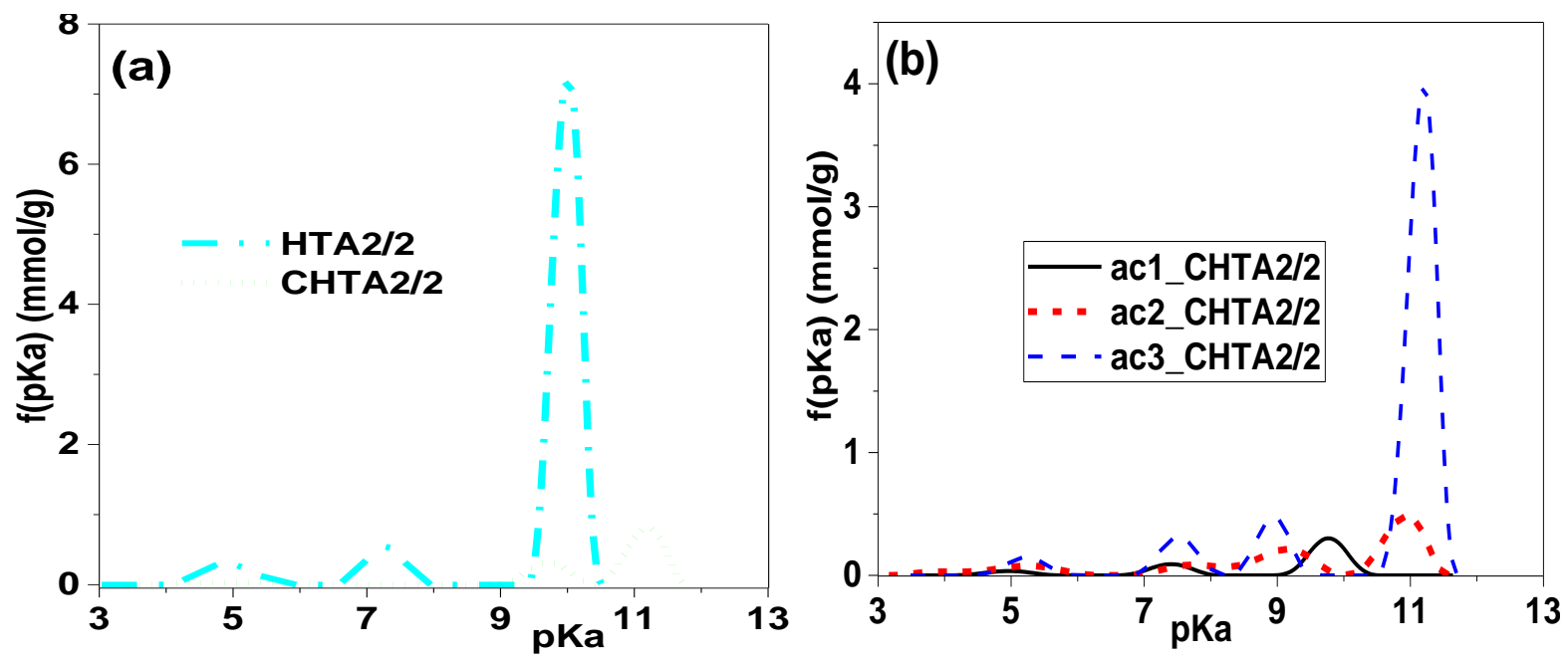

15 Figure 6: Density of functional groups as a function of $p K_{a}$, for carbonaceous materials 16 derived from TA2/2 sample: a) after HTC on one hand, and after HTC followed by 17 carbonisation on the other hand; b) after activation of the CHTA 2/2 sample. 
1 Table 1: Results of $p H_{P Z C}, p H_{\text {initial }}$ and potentiometric titration measurements: peak position

2 and numbers of groups (in parentheses: $(\mathrm{mmol} / \mathrm{g})$ ).

\begin{tabular}{lcccccccc}
\hline \multicolumn{1}{c}{ Samples } & $p H_{\text {initial }}$ & $p K_{a} 3-5$ & $p K_{a} 5-7$ & $p K_{a} 7-8$ & $p K_{a} 8-10$ & $p K_{a} 10-12$ & All & $p H_{P Z C}$ \\
\hline \multirow{2}{*}{ HTA2/2 } & n.d. & $\begin{array}{c}4.92 \\
(0.298)\end{array}$ & - & $\begin{array}{c}7.32 \\
(0.536)\end{array}$ & - & $\begin{array}{c}10.02 \\
(7.313)\end{array}$ & 8.15 & n.d. \\
\hline \multirow{2}{*}{ CHTA2/2 } & n.d. & - & $\begin{array}{c}5.04 \\
(0.030)\end{array}$ & - & $\begin{array}{c}9.72 \\
(0.315)\end{array}$ & $\begin{array}{c}11.19 \\
(0.810)\end{array}$ & 1.16 & n.d. \\
\hline \multirow{2}{*}{ ac1_CHTA2/2 } & \multirow{2}{*}{10.6} & $\begin{array}{c}4.96 \\
(0.036)\end{array}$ & - & $\begin{array}{c}7.38 \\
(0.091)\end{array}$ & $\begin{array}{c}9.76 \\
(0.302)\end{array}$ & - & 0.43 & n.d. \\
\hline \multirow{2}{*}{ ac2_CHCTA2/2 } & 9.7 & $\begin{array}{c}3.97 \\
(0.031)\end{array}$ & $\begin{array}{c}5.24 \\
(0.078)\end{array}$ & $\begin{array}{c}7.79 \\
(0.085)\end{array}$ & $\begin{array}{c}9.10 \\
(0.212)\end{array}$ & $\begin{array}{c}(0.480) \\
(0.93\end{array}$ & 0.89 & 9.31 \\
\hline \multirow{2}{*}{ ac3_CHCTA2/2 } & 10.7 & - & $\begin{array}{c}5.23 \\
(0.146)\end{array}$ & $\begin{array}{c}7.54 \\
(0.309)\end{array}$ & $\begin{array}{c}8.98 \\
(0.468)\end{array}$ & $\begin{array}{c}11.21 \\
(3.997)\end{array}$ & 4.92 & n.d. \\
\hline
\end{tabular}

3 n.d. non determined because not relevant for the objectives of this study

4

\section{$5 \quad$ 3.1.3 Scanning Electron microscopy (SEM) studies}

Figure 7 shows SEM images of the material CHTA2/2 at different magnifications. The

7 morphology of the sample did not change with activation time, see Figure SI 2 for images of

8 ac2_CHTA2/2 and ac3_CHTA2/2. The initial structure of agave was preserved, giving rise to

9 tubular carbon pores where carbon microspheres, probably produced by HTC of tannin and/or

10 dissolved (poly)saccharides (Braghiroli et al., 2015; Sanchez-Sanchez et al., 2016) were

11 attached.

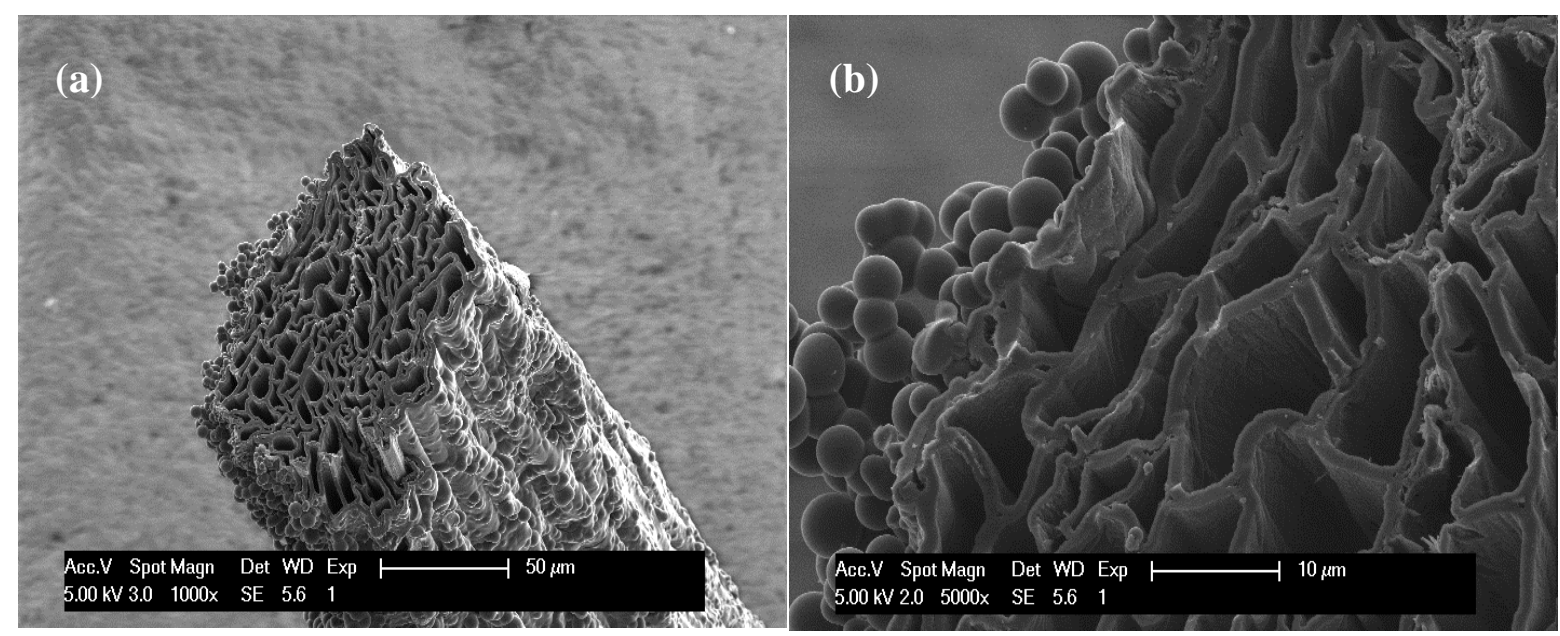

13 Figure 7: SEM images obtained with secondary electrons of CHTA2/2 at different

14 magnifications: (a) $1000 \times$; and (b) $5000 \times$. 
In order to get more insight into these materials, the five produced hydrochars were

2 investigated by FTIR. Figure 8a shows the spectra of HTA4/0 (pure tannin submitted to HTC)

3 at the top and that of HTA0/4 (pure agave submitted to HTC) at the bottom. In between are

4 the spectra of the three hydrochars produced from $\mathrm{T}$ and $\mathrm{A}$ at different values of $W$. All the

5 samples showed a broad band centred on around $3300 \mathrm{~cm}^{-1}$ and attributed to hydroxyl groups

6 (Mahmoudi et al., 2012). The diminution of intensity of the band around $2900 \mathrm{~cm}^{-1}$ from

7 HTA0/4 to HTA4/0 is due to the diminution of aliphatic $\mathrm{C}-\mathrm{H}$ stretching functions because

8 HTA0/4 was richer in hydrogen. Contrariwise, the addition of tannin made the band around

$91500 \mathrm{~cm}^{-1}$ become more intense, indicating that tannin tends to enrich the surface in hydroxyl

10 and carboxyl functional groups $(-\mathrm{OH}, \mathrm{C}=\mathrm{O}$ and $\mathrm{C}-\mathrm{O}$ stretching). This was confirmed by the

11 results of elemental analysis. Finally, the addition of tannin decreased slightly the stretching

$12 \mathrm{C}-\mathrm{C}$ vibration corresponding to the series of peaks between 1350 and $850 \mathrm{~cm}^{-1}$. This broad

13 band, becoming wider with $W$, confirms the enrichment of the surface with C-O groups. Other

14 hydrochars (HTA1/3, HTA2/2 and HTA3/1) had intermediary characteristics.

Figure $8 \mathrm{~b}$ shows a fibre present in hydrochar HTA2/2: it came from agave and a

16

squared area was chosen for studying its chemical composition. Figure $8 \mathrm{c}$ shows the resultant chemical mapping wherein the red colour corresponds to the composition of the Agave americana hydrochar (HTA0/4), and the green colour corresponds to that of the Tannin hydrochar (HTA4/0). $35.2 \%$ of the analysed area was thus ascribed to agave hydrochar whereas $61.9 \%$ was attributed to tannin hydrochar. Only a residual $2.9 \%$ could not be fitted with these two main components, which was assumed to occur from experimental error or to parallel reactions produced by the combination of tannin and agave during the hydrothermal treatment. The higher amount of tannin hydrochar found here supports the morphological observations. Therefore, we can confirm that when T was submitted to HTC with A, the latter 
1 remained in the form of hydrochar microspheres covering the surface, thus providing

2 microporous volume to the resultant carbon materials.

3
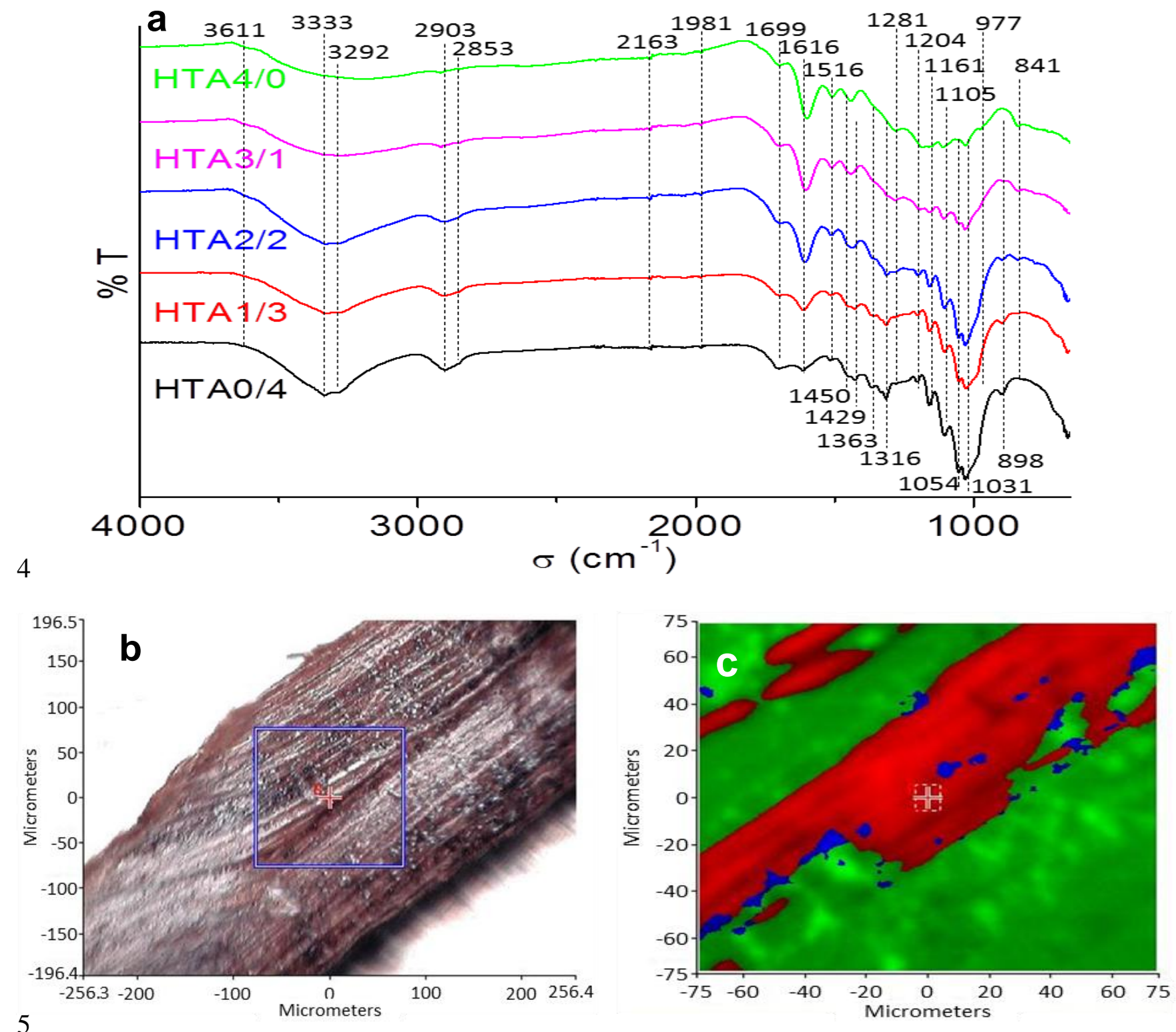

6 Figure 8: (a) FTIR spectra of HTAW materials; (b) optical microscopy image of a fibre of

7 HTA2/2; and (c) chemical mapping of the area selected in (b) ( $\square$ : agave americana

8 hydrochar (HTA0/4), : mimosa tannin hydrochar (HTA4/0), $\mathbf{\square}$ : insignificant component). 


\subsection{Tetracycline adsorption}

TC adsorption was investigated in aqueous phase on ac2_CHTA2/2, since this AC had the highest $S_{\text {Tot }}: 152 \mathrm{~m}^{2} / \mathrm{g}$. This AC had a $S_{B E T}$ of $1068 \mathrm{~m}^{2} / \mathrm{g}$ and a $S_{N L D F T}$ of $1292 \mathrm{~m}^{2} / \mathrm{g}$. Figure 9 shows the effect of $\mathrm{pH}$ and temperature on the TC adsorption capacity, $q_{e}$, onto ac2_CHTA2/2. pH slightly influenced the adsorption capacity at 35 and $50^{\circ} \mathrm{C}$, but had a significant influence at $25^{\circ} \mathrm{C}$. The $p H_{P Z C}$ of this $\mathrm{AC}$ was 9.3 , consequently the adsorbent surface was negatively charged (attracting cations) at $\mathrm{pH} \mathrm{10,} \mathrm{and} \mathrm{positively} \mathrm{charged}$ (attracting anions) at pH 4.5 or 7. According to Zhang et al. (Zhang et al., 2015), TC molecule can be charged either positively $(\mathrm{pH}<3.32)$, neutrally $(3.3<\mathrm{pH}<7.8)$, or negatively $(\mathrm{pH}>$ 7.8), due to the existence of three functional groups. At $\mathrm{pH} 10$, the AC surface and TC were both negatively charged, so electrostatic repulsion between them probably caused the decrease of the amount of adsorbed $\mathrm{TC}$ at $25^{\circ} \mathrm{C}$. At $\mathrm{pH} 4.5$ or 7 , the $\mathrm{AC}$ surface was positively charged while the TC molecule was neutral. TC adsorption capacities clearly increased with temperature from 25 to $50^{\circ} \mathrm{C}$, and this fact was confirmed at the $3 \mathrm{pH}$ tested, especially when increasing the basicity. This experimental observation might appear against the thermodynamic principles because adsorption usually decreases when the temperature increases. However, adsorption in aqueous solution is a much more complex process than in the gas phase. $\Delta G^{\circ}$ depends on $\Delta H^{\circ}$ and $\Delta S^{\circ}$, which were both positives as can be seen in Table 2. Positive values of $\Delta H^{\circ}$ and $\Delta S^{\circ}$ have also been reported by other authors for TC adsorption (Acosta et al., 2016; Erşan et al., 2013), using different adsorbents and initial concentrations. $\Delta H^{\circ}$ should be negative for an adsorption process but TC adsorption on ac2_CHCTA2/2 might include an endothermic process (break of hydrogen bonds) and an exothermic process (adsorption), the former predominating over the latter. Increasing the adsorption temperature weakens the hydrogen bonds formed between water molecules on one hand, and between water molecules and solute or adsorbent on the other hand and also 
1 enhances the diffusion into the pores. This was already observed by other authors (Fontecha-

2 Cámara et al., 2006) who pointed out that the formation of hydrogen bonds between solute

3 and solvent, favored at low temperatures, can modify the shape and size of solute molecules

4 so that they can no more access the micropores of the adsorbent. Thus, temperature increase

5 may possibly weaken the hydrogen bonds and favor solute uptake on the adsorbent. $\Delta S^{\circ}$ was

6 also positive, which suggests higher randomness at the adsorbate-solution interface when

7 compared to the concentrated liquid phase.

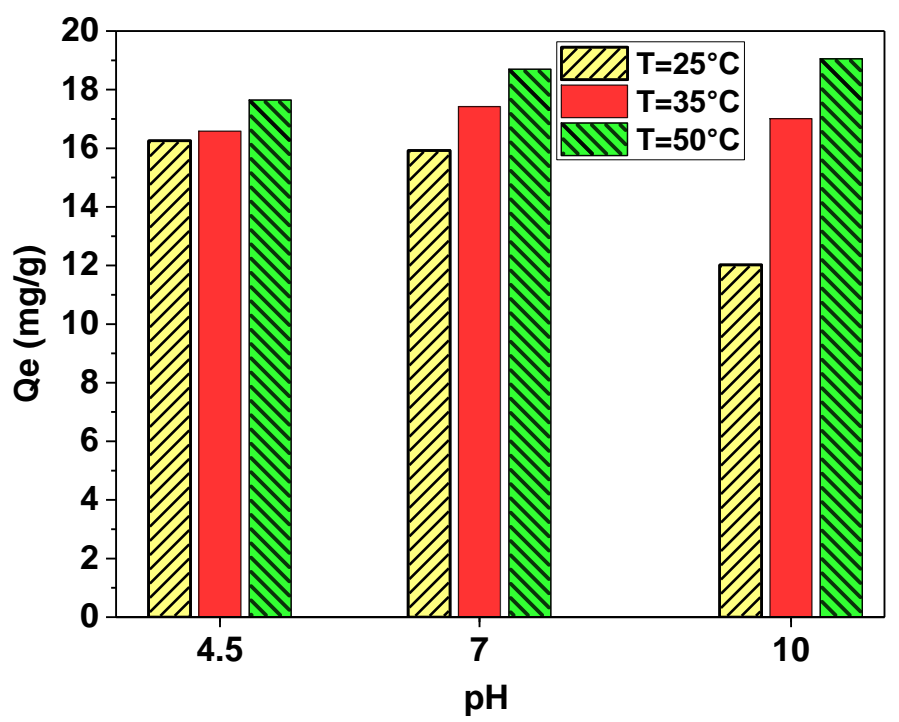

9 Figure 9: Effect of $\mathrm{pH}$ and temperature on the adsorption of TC on ac2_CHTA2/2 at

10 equilibrium $\left(C_{0}=10 \mathrm{mg} / \mathrm{L}, m=0.05 \mathrm{~g}, V=100 \mathrm{~mL}\right)$.

11

12 Table 2: Thermodynamic parameters for the adsorption of TC onto ac2_CHTA2/2 activated

13 carbon at different temperatures (initial TC concentration of $10 \mathrm{mg} / \mathrm{L}$ ).

\begin{tabular}{lcccccc}
\hline \multirow{2}{*}{ Sample } & $\mathrm{pH}$ & $\Delta H^{\circ}(\mathrm{kJ} / \mathrm{mol})$ & $\Delta S^{\circ}(\mathrm{J} / \mathrm{mol} / \mathrm{K})$ & \multicolumn{3}{c}{$\Delta G^{\circ}(\mathrm{kJ} / \mathrm{mol})$} \\
\cline { 5 - 7 } & & & & $25^{\circ} \mathrm{C}$ & $35^{\circ} \mathrm{C}$ & $50^{\circ} \mathrm{C}$ \\
\hline \multirow{2}{*}{ ac2_CHTA2/2 } & 7 & 12.7 & 56.5 & -4.2 & -4.7 & -5.6 \\
& 7 & 22.3 & 87.8 & -3.8 & -5.1 & -6.0 \\
& 10 & 37.7 & 135.1 & -2.0 & -5.0 & -5.5 \\
\hline
\end{tabular}

14 


\subsection{Kinetic studies}

Figure 10a shows the adsorption of TC onto ac2_CHTA2/2 and F300 as a function time at $25^{\circ} \mathrm{C}$ and at $\mathrm{pH}$ 4. The $\mathrm{F} 300$ commercial activated carbon was used for the sake of comparison, and its characterisation was detailed elsewhere (Selmi et al., 2017). In brief, F300 has the following pore texture parameters: $S_{B E T}=884 \mathrm{~m}^{2} / \mathrm{g}, S_{N L D F T}=1003 \mathrm{~m}^{2} / \mathrm{g}$, $V_{\text {mic }, N L D F T}=0.34 \mathrm{~cm}^{3} / \mathrm{g}$. The maximum adsorption was obtained after $4 \mathrm{~h}$ for ac2_CHTA2/2 and after $7 \mathrm{~h}$ for F300. The latter presented a lower TC adsorption capacity because of its lower $S_{B E T}$, and the time needed for equilibrium was also higher because F300 has essentially a narrow microporosity whereas ac2_CHTA2/2 has supermicropores and some mesoporosity. Figure $10 \mathrm{~b}$ shows the adsorption of TC at different initial concentrations onto ac2_CHTA2/2 as a function time. When the concentration increased, the sorption rate of TC increased, as well as the amount adsorbed at equilibrium. The increase of TC concentration from 0.5 to 100 $\mathrm{mg} / \mathrm{L}$ also increased the time needed to reach equilibrium, from 25 to $200 \mathrm{~min}$; this might be due to diffusional resistance, given the fact that TC molecule size is similar to the ac2_CHTA2/2 micropore size (Rivera-Utrilla et al., 2013).

Table SI 4 and Table SI 5 show the parameters derived from the nonlinear fits of kinetic models to the experimental data, as well as the calculated and experimental equilibrium sorption capacities, rate constants $\left(k_{1}\right.$ and $\left.k_{2}\right)$, error $\left(\chi^{2}\right)$, determination coefficient $\left(R^{2}\right)$, and the initial adsorption rates $\left(h_{1}\right.$ and $\left.h_{2}\right)$. Table SI 4 presents the corresponding experimental adsorption capacities at equilibrium: 51.35 and $28.58 \mathrm{mg} / \mathrm{g}$ for ac2_CTA2/2 and F300, respectively. Generally, $q_{e}$ calculated by PSO was always closer to the experiment than the value obtained from the PFO model. Moreover, determination coefficients obtained by PSO were always higher than those obtained by PFO model, in agreement with previous results on the adsorption of methylene blue onto Agave americana fibres (Ben Hamissa et al., 2013). In addition, the values of $h_{2}$ were 2.48 and $0.15 \mathrm{mg} /(\mathrm{g} . \mathrm{min})$ for ac2_CHTA2/2 and F300, 
1 respectively, demonstrating that TC adsorption onto ac2_CHTA2/2 was much faster than onto 2 F300.
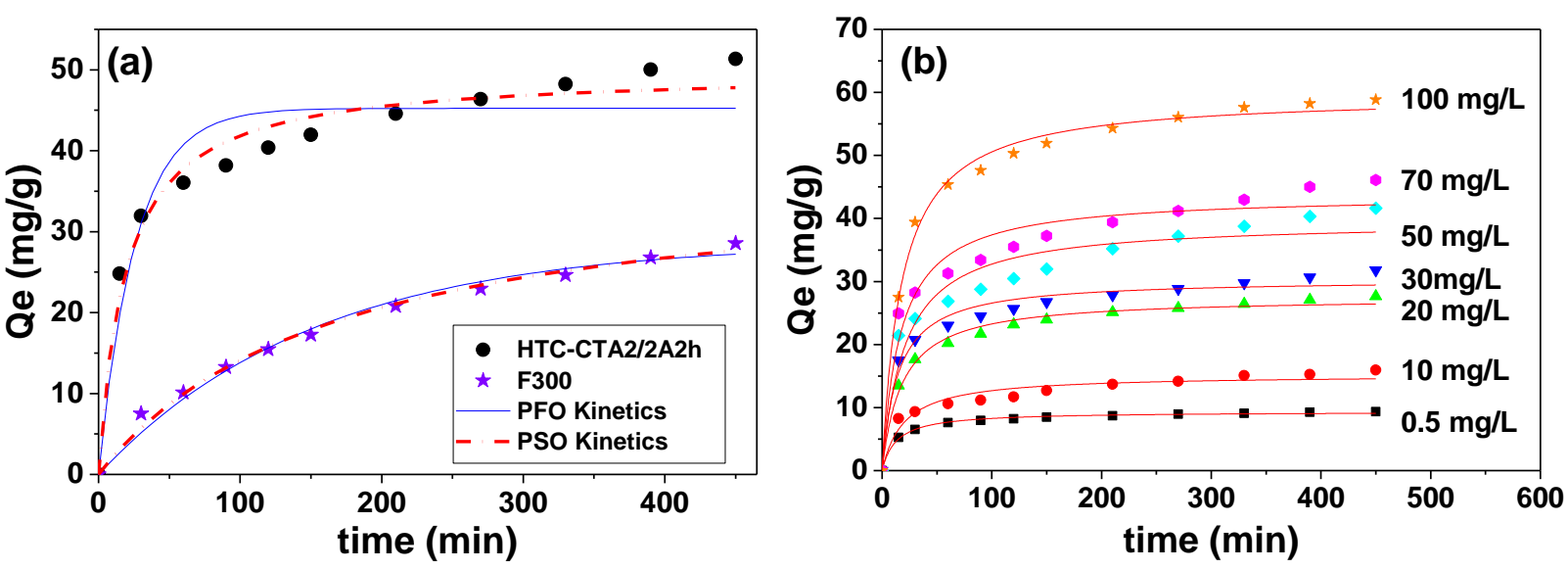

Figure 10: Nonlinear fit to the kinetics of TC adsorption onto: (a) ac2_CHTA2/2 and F300 with PFO and PSO models at $\mathrm{pH} 4,25^{\circ} \mathrm{C}$ and $C_{0}=100 \mathrm{mg} / \mathrm{L}$; and (b) onto ac2_CHTA2/2 only with PSO model at different initial concentrations for $\mathrm{pH} 7$ at $25^{\circ} \mathrm{C}$.

Table SI 5 shows that the determination coefficients, $R^{2}$, for the PFO kinetic models obtained for all studied initial concentrations were sometimes not that high. The best fit was obtained with the PSO kinetic model for all initial concentrations used. Similar results were obtained for the adsorption of Congo red dye onto an activated carbon derived from coir pith (Namasivayam and Kavitha, 2002). The initial adsorption rates increased with TC initial concentration.

\section{4 isotherm studies}

Figure 11 shows TC adsorption isotherms onto ac2_CHTA2/2. TC adsorption capacity increased with $C_{0}$. Because of their simplicity, Langmuir (Langmuir, 1918) and Freundlich (Freundlich, 1906) models were applied to analyse the experimental data. The parameters of each model, calculated by regression from non-linear forms of Langmuir and Freundlich 
1 isotherms are summarised in Table SI 6. Langmuir model led to the best fit, with

2 determination coefficients between 0.968 and 0.995 . Moreover, the monolayer saturation

3 capacity, $q_{\max }$, was relatively close to $q_{\text {exp }}$. As for Freundlich isotherm, the values of $R^{2}$

4 (between 0.773 and 0.943 ) were much lower with respect to those of the Langmuir model.

5 The values of Freundlich exponent, $n$, were found to be higher than 1, indicating that TC

6 adsorption onto ac2_CHTA2/2 is favourable.

7
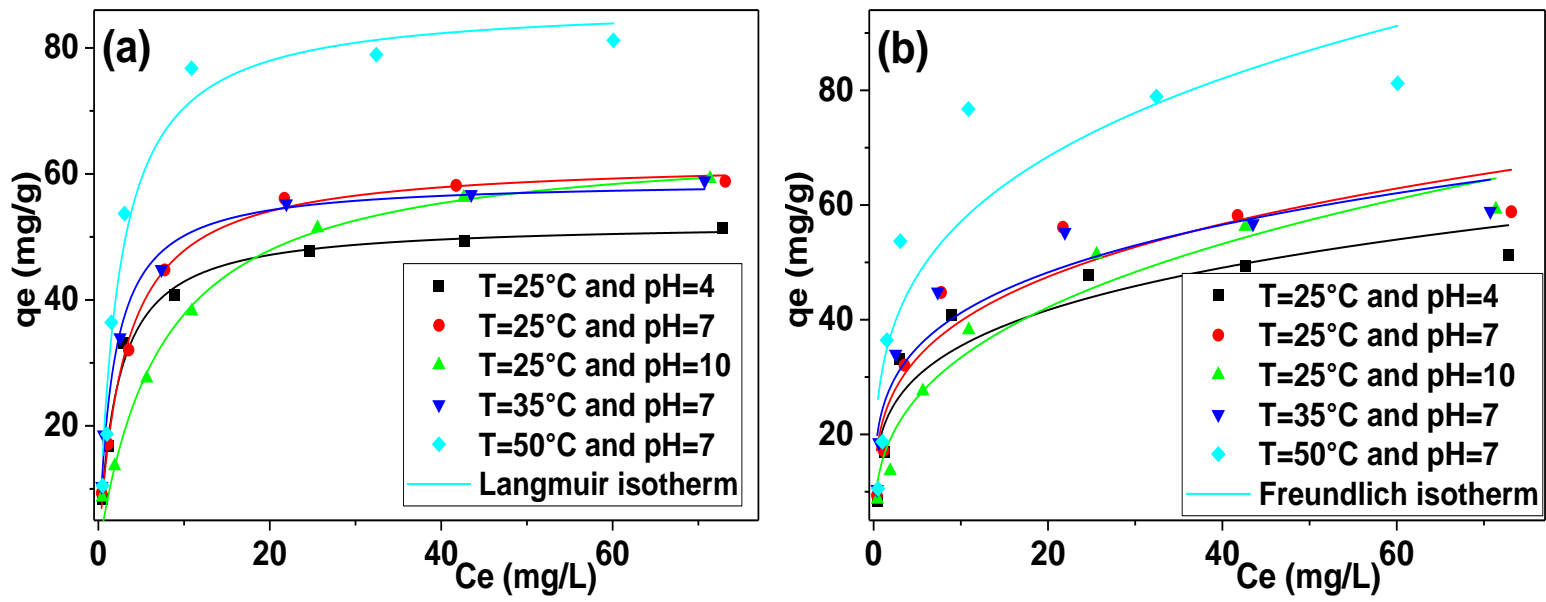

Figure 11: Adsorption isotherms of TC onto ac2_CHTA2/2, showing the effects of $\mathrm{pH}$ and temperature: (a) fit with Langmuir model, and (b) fit with Freundlich model.

In order to have an idea about the efficiency of the tested adsorbents materials for the removal of TC, a comparison was made with other adsorbents reported in the literature as summarised in Table 3. Such comparison was based on the adsorption capacity $q_{e}(\mathrm{mg} / \mathrm{g})$. As can be observed, the ac2_CHTA2/2 material has adsorption capacities in the range of those presented by other materials of similar $S_{B E T}$. The adsorption capacities obtained by Ncibi and Mika (Ncibi and Mika, 2015) were clearly higher, but their materials were carbon nanotubes and, probably, a very narrow microporosity existed inside and between the nanotubes walls not accessible to nitrogen, and/or was underestimated by the BET equation. On the contrary, it is not physically possible to have ACs with areas higher than $2630 \mathrm{~m}^{2} / \mathrm{g}$ (Fierro et al., 2010b; 
1 Schlapbach and Zuttel, 2001), whereas Zhang et al. (Zhang et al., 2015) reported a surface

2 area of $2900 \mathrm{~m}^{2} / \mathrm{g}$.

3 Table 3: TC removal onto different adsorbents.

\begin{tabular}{cccccccl}
\hline $\begin{array}{c}S_{B E T} \\
\left(\mathrm{~m}^{2} / \mathrm{g}\right)\end{array}$ & $\begin{array}{c}C_{0} \\
(\mathrm{mg} / \mathrm{L})\end{array}$ & $\begin{array}{c}\text { Adsorbent } \\
(\mathrm{g} / \mathrm{L})\end{array}$ & $\begin{array}{c}T \\
\left({ }^{\circ} \mathrm{C}\right)\end{array}$ & $\mathrm{pH}$ & $p H_{P Z C}$ & $q_{e}(\mathrm{mg} / \mathrm{g})$ & \multicolumn{1}{c}{ Reference } \\
\hline 56 & n.a & n.a & n.a & n.a & n.a & 24 & (Lian et al., 2013) \\
\hline 61 & 100 & 1 & & & 7.2 & 24 & \\
484 & 300 & 0.5 & 25 & $6.5-7.5$ & 7.8 & 265 & (Acosta et al., 2016) \\
700 & 300 & 0.5 & & & 10.7 & 316.6 & \\
\hline 67 & 80 & 1 & 25 & 7.0 & n.a & 23.3 & (Liao et al., 2013) \\
\hline 158 & & & & & & 391 & \\
382 & 100 & 0.1 & 25 & 7.0 & n.a & 507 & (Ncibi and Mika, 2015) \\
576 & & & & & & 554 & \\
\hline 680 & 100 & 0.06 & Room & 7.0 & n.a & 303.3 & (Vu et al., 2010) \\
\hline 1008 & 450 & 0.4 & 25 & 2.0 & n.a & 339 & (Huang et al., 2013) \\
\hline 1455 & 400 & 1 & 35 & 5.7 & 5.86 & 202 & (Güzel and Hasan, 2016) \\
\hline 1463 & 660 & 1 & 25 & 5.0 & n.a & 535 & (Sun et al., 2013) \\
\hline 2806 & 100 & 0.1 & 25 & 3.68 & n.a & 897.6 & (Zhang et al., 2015) \\
\hline$>1220$ & 700 & 1 & 25 & 7 & 7.7 & 471.1 & (Rivera-Utrilla et al., 2013) \\
\hline 1068 & 400 & 0.5 & 25 & 7.0 & 9.3 & 239.4 & This study \\
884 & 100 & 1 & 25 & 4.5 & 8.0 & 28.6 & \\
\hline
\end{tabular}

n.a. (non available)

5

9 (i.e., $0 / 4 ; 1 / 3 ; 2 / 2 ; 3 / 1$ and 4/0). The first series, CTAW, was directly pyrolysed at $900^{\circ} \mathrm{C}$ and

10 the second one, CHTAW, was made through a hydrothermal carbonisation (HTC) step prior

11 to pyrolysis. These two carbon series were completely different, in terms of both porous

12 texture and chemical composition. Thus, the CTAW series had a less developed pore texture

13 than the CHTAW series. The CHTAW series had higher $\mathrm{H} / \mathrm{C}$ atomic ratios indicating a lower

14 aromatisation. Submitting a blend of T and A to HTC produced an increase of carbon yield,

15 the highest one being obtained for the sample CHTA2/2, i.e., with $W=2 / 2$. 
The CHTA2/2 sample was activated under $\mathrm{CO}_{2}$ flowing at $900^{\circ} \mathrm{C}$ for 1,2 or 3 hours to

2 produce ACs with $S_{B E T}$ as high as $1200 \mathrm{~m}^{2} / \mathrm{g}$, and with much more chemical groups on their

3 surface. The appropriate selection of the synthesis conditions thus allowed obtaining high-

4 surface area ACs with similar carbon yields and average pore diameters as those of non-

5 activated, low-surface area carbon materials.

6 The one activated for 2 hours, ac2_CHTA2/2, was tested for tetracycline (TC)

7 adsorption and compared to a commercial activated carbon, F300. Adsorption equilibrium

8 was reached much faster, $4 \mathrm{~h}$, for ac2_CHTA2/2 than for F300, 7h, due to the presence of

9 macropores and mesopores provided by Agave giving access to an important microporosity.

10 TC adsorption was spontaneous onto ac2_CHTA2/2, and the corresponding adsorption

11 kinetics was adequately fitted by a pseudo-second-order model. TC adsorption essentially

12 depends on surface area, and the results reported herein are in the range of those reported in 13 the open literature.

14

\section{Acknowledgements}

16 The authors from Sousse University gratefully acknowledge the financial support from

17 the Tunisian Ministry of Higher Education and Scientific Research, and the EU-METALIC

18 Erasmus Mundus project. 


\section{References}

2 Acosta, R., Fierro, V., Martinez de Yuso, A., Nabarlatz, D., Celzard, A., 2016. Tetracycline adsorption onto activated carbons produced by $\mathrm{KOH}$ activation of tyre pyrolysis char. Chemosphere 149, 168-176.

Altenor, S., Ncibi, M.C., Emmanuel, E., Gaspard, S., 2012. Textural characteristics, physiochemical properties and adsorption efficiencies of Caribbean alga Turbinaria turbinata and its derived carbonaceous materials for water treatment application. Biochem Eng J 67, 35-44.

Ben Hamissa, A.M., Brouers, F., Ncibi, M.C., Seffen, M., 2013. Kinetic Modeling Study on

Bergius, F., 1915. Zeitschriftfur Komprimierte und Flussige Gase. 17.

Braghiroli, F.L., 2014. Polyphénols végétaux traités par voie humide: synthèse de carbones Université de Lorraine, pp. 27-32.

Braghiroli, F.L., Fierro, V., Izquierdo, M.T., Parmentier, J., Pizzi, A., Celzard, A., 2012. Nitrogen-doped carbon materials produced from hydrothermally treated tannin. Carbon $50,5411-5420$.

Braghiroli, F.L., Fierro, V., Izquierdo, M.T., Parmentier, J., Pizzi, A., Celzard, A., 2014. Kinetics of the hydrothermal treatment of tannin for producing carbonaceousmicrospheres. Bioresource Technol. 151, 271-277. 
1 Braghiroli, F.L., Fierro, V., Parmentier, J., Vidal, L., Gadonneix, P., Celzard, A., 2015. Hydrothermal carbons produced from tannin by modification of the reaction medium: Addition of H+ and Ag+. Ind Crops Prod 77, 364-374.

Braghiroli, F.L., Fierro, V., Szczurek, A., Gadonneix, P., Ghanbaja, J., Parmentier, J., Medjahdi, G., Celzard, A., 2017. Hydrothermal Treatment of Tannin: A Route to Porous Metal Oxides and Metal/CarbonvHybrid Materials. inorganics 19, 7.

Brun, N., Edembe, L., Gounel, S., Mano, N., Titirici, M.M., 2013. Emulsion-Templated Macroporous Carbons Synthesized By Hydrothermal Carbonization and their Application for the Enzymatic Oxidation of Glucose. ChemSusChem 6, 701-710.

Brunauer, S., Emmet, P.H., Teller, E., 1938. Adsorption of gases in multimolecular layers. J American Chem Society, 309-319.

Choi, Y.-K., Cho, M.-H., Kim, J.-S., 2016. Air gasification of dried sewage sludge in a twostage gasifier. Part 4: Application of additives including Ni-impregnated activated carbon for the production of a tar-free and H2-rich producer gas with a low NH3 content. Internat J Hydr Energ 41, 1460-1467.

Denisa, H.-J., Mykola, S., Gao, G.L., Teresa, J.B., 2009. Combined Effect of Nitrogen- and Oxygen-Contaning functional Group of Microporous Activated Carbon on is Electrochemical Performance in Supercapacitors. Adv Funct Mater 9, 438-447.

Dirany, I., Sirés, I., Oturan, N., Ozcan, A., Oturan, M., 2012. Electrochemical treatment of the antibiotic sulfachloropyridazine: kinetics, reaction pathways, and toxicity evolution. Environ Sci Technol, 4074-4082.

Dubinin, M.M., 1989. Fundamentals Of The Theory Of Adsorption In Micropores Of Carbon Adsorbents: Characteristics Of Their Adsorption Properties And Microporous Structures. Carbon 27, 457-567. 
1 Erşan, M., Bağda, E., Bağda, E., 2013. Investigation of kinetic and thermodynamic characteristics of removal of tetracycline with sponge like, tannin based cryogels. Colloids and Surfaces B: Biointerfaces 104, 75-82.

Fierro, V., Muñiz, G., Basta, A.H., El-Saied, H., Celzard, A., 2010a. Rice straw as precursor of activated carbons: Activation with ortho-phosphoric acid. J Hazard Mater 181, 27-34.

Fierro, V., Szczurek, A., Zlotea, C., Marêché, J.F., Izquierdo, M.T., Albiniak, A., Latroche, M., Furdin, G., Celzard, A., 2010b. Experimental evidence of an upper limit for hydrogen storage at 77K on activated carbons. Carbon 48, 1902-1911.

Fierro, V., Torné-Fernández, V., Celzard, A., Montané, D., 2007. Influence of the demineralisation on the chemical activation of Kraft lignin with orthophosphoric acid. $\mathbf{J}$ Hazard Mater 149, 126-133.

Fontecha-Cámara, M.A., López-Ramón, M.V., Álvarez-Merino, M.A., Moreno-Castilla, C., 2006. About the endothermic nature of the adsorption of the herbicide diuron from aqueous solutions on activated carbon fiber. Carbon 44, 2335-2338.

Freundlich, H., 1906. Over the adsorption in solution. J Phys Chem 57, 385-471.

Ghouma, I., Mejdi, J., Sophie, D., Lionel, L., Camelia, M.G., Abdelmottaleb, O., 2015. Activated carbon prepared by physical activation of olive stones for the removal of $\mathrm{NO}_{2}$ at ambient temperature. Compt Rend Chim 18, 63-74.

Güzel, F., Hasan, S., 2016. Adsorptive efficacy analysis of novel carbonaceous sorbent derived from grape industrial processing waste stowards tetracycline in aqueous solution. J Taiwan Inst Chem Eng 4, 236-240.

Ho, Y.S., McKay, G., 1999. Pseudo-second order model for sorption processes. Process Biochem 34, 451-465. 
1 Huang, L., Shi, C., Zhang, B., Niu, S., Gao, B., 2013. Characterization of Activated Carbon Fiber by Microwave Heating and the Adsorption of Tetracycline Antibiotics. Sep Sci Technol 48, 1356-1363.

Jagiello, J., 1994. Stable Numerical Solution of the Adsorption Integral Equation Using Splines. Langmuir 10, 2778-2785.

Jagiello, J., Ania, C., Parra, J.B., Cook, C., 2015. Dual gas analysis of microporous carbons using 2D-NLDFT heterogeneous surface model and combined adsorption data of $\mathrm{N} 2$ and CO 2. Carbon 91, 330-337.

Jagiello, J., Bandosz, T.J., Putyera, K., Schwarz, J.A., 1995. Determination of proton affinity distributions for chemical systems in aqueous environments using a stable numerical solution of the adsorption intergral equation J Colloid Interface Sci 172, 341-346.

Khan, M.N., Sarwar, A., 2007. Determination of Points of Zero Charge of Natural and Treated Adsorbents. Surf Rev Lett 14, 461-469.

Kovalova, L., Siegrist, H., Singer, H., Wittmer, A., McArdell, C.S., 2012. Hospital wastewater treatment by membrane bioreactor: performance and efficiency for organic micropollutant elimination. . Environ Sci Technol, 1536-1545.

Lagergren, S., 1898. Zur Theorie der Sogenannten Adsorption Gelöster Stoffe, Kungliga Svenska Vetenskapsakade- miens. Handlingar 24, 1-39.

Langmuir, I., 1918. The adsorption of gases on plane surfaces of glass, mica, and platinum. J American Chem Society 40, 1361.

Li, Q., Qi, Y., Gao, C., 2015. Chemical regeneration of spent powdered activated carbon used in decolorization of sodium salicylate for the pharmaceutical industry. J Clean Prod 86, 424-431. 
1 Lian, F., Song, Z., Liu, Z., Zhu, L., Xing, B., 2013. Mechanistic understanding of tetracycline sorption on waste tire powder and its chars as affected by $\mathrm{Cu} 2+$ and $\mathrm{pH}$. Environ Pollu $178,264-270$.

Liao, P., Zhan, Z., Dai, J., Wu, X., Zhang, W., Wang, K., Yuan, S., 2013. Adsorption of tetracycline and chloramphenicol in aqueous solutions by bamboo charcoal: A batch and fixed-bed column study. Chem Eng J 228, 496-505.

Ling-Ping, X., Zheng-Jun, S., Feng, X., Run-Cang, S., (2012) Hydrothermal carbonization of lignocellulosic biomass. Bioresource Technol. 4, 619-623.

Luca, F., Daniele, B., Daniele, C., Marco, B., 2014. Hydrothermal Carbonization of Biomass: Design of a Batch Reactor and Preliminary Experimental Results. Chem Eng 37, 55-60.

Mahmoudi, K., Hamdi, N., Kriaa, A., Srasra, S., 2012. Adsorption of Methyl Orange Using Activated Carbon Prepared from Lignin by ZnCl2 Treatment. Russian J Phys Chem A $86,1294-1300$.

Molina-Sabio, M., Rodríguez-Reinoso, F., 2004. Role of chemical activation in the development of carbon porosity. Colloid Surf A: Physchem Eng Asp 241, 15-25.

Namasivayam, C., Kavitha, D., 2002. Removal of Congo Red from water by adsorption onto activated carbon prepared from coir pith, an agricultural solid waste. Dyes Pigments, 47.

Ncibi, M.C., Mika, S., 2015. Optimized removal of antibiotic drugs from aqueous solutions usingsingle, double and multi-walled carbon nanotubes. J Hazard Mater 298, 102-110.

Njoku, V.O., Foo, K.Y., Asif, M., Hameed, B.H., 2014. Preparation of activated carbons from rambutan (Nephelium lappaceum) peel by microwave-induced $\mathrm{KOH}$ activation for acid yellow 17 dye adsorption. Chem Eng J 250, 198-204.

Rivera-Utrilla, J., Gómez-Pacheco, C.V., Sánchez-Polo, M., López-Peñalver, J.J., OcampoPérez, R., 2013. Tetracycline removal from water by adsorption/bioadsorption on activated carbons and sludge-derived adsorbents. J Environ Manage 131, 16-24. 
1 Rodríguez-Estupiñan, P., Giraldo, L., Moreno-Piraján, J.C., 2013. Energetic changes in the surface of activated carbons and relationship with $\mathrm{Ni}(\mathrm{II})$ adsorption from aqueous solution. Appl Surf Sci 286, 351-357.

Ryu, J., Suh, Y.-W., Suh, D.J., Ahn, D.J., 2010. Hydrothermal preparation of carbon microspheres from mono-saccharides and phenolic compounds. Carbon 48, 1990-1998.

Sanchez-Sanchez, A., Martinez de Yuso, A., Braghiroli, F.L., Izquierdo, M.T., Alvarez, E.D., Perez-Cappe, E., Mosqueda, Y., Fierro, V., Celzard, A., 2016. Sugarcane molasses as a pseudocapacitive material for supercapacitors. RSC Adv 6, 88826-88836.

Schaefer, S., Fierro, V., Izquierdo, M.T., Celzard, A., 2016. Assessment of hydrogen storage in activated carbons produced from hydrothermally treated organic materials. Internat $\mathbf{J}$ Hydr Energ 41, 12146-12156.

Schaefer, S., Muñiz, G., Izquierdo, M.T., Mathieu, S., Ballinas-Casarrubias, M.L., GonzálezSánchez, G., Celzard, A., Fierro, V., 2017. Rice straw-based activated carbons doped with SiC for enhanced hydrogen adsorption. Internat J Hydr Energ 42, 11534-11540.

Schlapbach, L., Zuttel, A., 2001. Hydrogen-storage materials for mobile applications. Nature 414, 353-358.

Selmi, T., Seffen, M., Sammouda, H., Sandrine, M., Jagiello, J., Celzard, A., Fierro, V., 2017. Physical meaning of the parameters used in fractal kinetic and generalized adsorption models of Brouers-Sotolongo. Submitted to Adsorption.

Seredych, M., Biggs, M.J., Bandosz, T.J., 2016. Oxygen reduction on chemically heterogeneous iron-containing nanoporous carbon: The effects of specific surface functionalities. Microporous Mesoporous Mater 221, 137-149.

Sethia, G., Sayari, A., 2016. Activated carbon with optimum pore size distribution for hydrogen storage. Carbon 99, 289-294. 
1 Sun, Y., Yue, Q., Gao, B., Wang., Y., Gao, Y., Li, Q., 2013. Preparation of highly developed mesoporous activated carbon by $\mathrm{H}_{4} \mathrm{P}_{2} \mathrm{O}_{7}$ activation and its adsorptionbehavior for oxytetracycline. Powder Technol 249, 54-62.

Szczurek, A., Amaral-Labat, G., Fierro, V., Pizzi, A., Celzard, A., 2011. Bimodal activated carbons derived from resorcinol-formaldehyde cryogels. Sci Technol Adv Mater 12.

Thommes, M., Kaneto, K., Neimark, A.V., Olivier, J.P., Rodriguez-Reinoso, F., Rouquerol, J., Sing, K.S.W., 2015. Physisorption of gases, with special reference to the evaluation of surface area and pore size distribution (IUPAC Technical Report),. Pure Appl Chem 9e10, 1051e1069.

Vu, B.K., Snisarenko, O., Lee, H.S., Shin, E.W., 2010. Adsorption of tetracycline on La-impregnated MCM-41 materials. Environmental Technology 31, 233-241.

Washburn, E.W., 1921. The dynamics of capillary flow. Phys Rev 17, 273-283.

Zhang, D., Yin, J., Zhao, J., Zhu, H., Wang, C., 2015. Adsorption and removal of tetracycline from water by petroleum coke-derived highly porous activated carbon. J Environ Chem Eng 3, 1504-1512.

Zhao, W., Fierro, V., Zlotea, C., Aylon, E., Izquierdo, M.T., Latroche, M., Celzard, A., 2011. Optimization of activated carbons for hydrogen storage. Internat J Hydr Energ 36, 11746-11751.

Zietzschmann, F., Stützer, C., Jekel, M., 2016 Granular activated carbon adsorption of organic micro-pollutants in drinking water and treated wastwater--Aligning breakthrough curves and capacities. Water Res 7, 180. 


\section{$1 \quad$ List of tables}

2 Table 1: Results of $p H_{P Z C}, p H_{\text {Initial }}$ and potentiometric titration measurements: peak position

3 and numbers of groups (in parentheses: $(\mathrm{mmol} / \mathrm{g})$ )

4 Table 2: Thermodynamic parameters for the adsorption of TC onto ac2_CHTA2/2 activated

5 carbon at different temperatures (initial TC concentration of $10 \mathrm{mg} / \mathrm{L}$ ).

6 Table 3: TC removal onto different adsorbents.

7

8 


\section{$1 \quad$ Figure captions}

2 Figure 1: Van Krevelen diagrams of: (a) Agave, Tannin and HTAW series; and (b) CTAW, 3 CHTAW and act_CHTA2/2 series.

4 Figure 2 : (a) Total yield to hydrochar (HTAW), carbon (CHTAW and CTAW) or activated 5 carbon (act_CHTA2/2); and (b) Experimental (full symbols) and theoretical (empty symbols) 6 carbon yield: CTAW and CHTAW as a function of $W$.

7 Figure 3: (a, c, e) $\mathrm{N}_{2}$ adsorption-desorption isotherms at $-196^{\circ} \mathrm{C}$; and $(\mathrm{b}, \mathrm{d}, \mathrm{f})$ corresponding 8 PSDs.

9 Figure 4: Correlation between total yields, $Y_{T}$, and: (a) total pore volume, $V_{0.97}$; (b) specific surface area, $S_{B E T}$; (c) $\%$ of micropore volume from NLDFT, $\Phi_{m i c, N L D F T}(\%)$; and (d) average

11 pore diameter of CTAW, CHTAW and act_CHTA2/2 series.

12 Figure 5: (a) Cumulative intrusion/extrusion of mercury; and (b) corresponding pore size 13 distributions of the act_CHTA2/2 series.

14 Figure 12: Density of functional groups as a function of $p K_{a}$, for carbonaceous materials derived from TA2/2 sample: a) after HTC on one hand, and after HTC followed by carbonisation on the other hand; b) after activation of the CHTA 2/2 sample.

17 Figure 7: SEM images obtained with secondary electrons of CHTA2/2 at different 18 magnifications: (a) $1000 \times$; and (b) $5000 \times$.

19 Figure 8: (a) FTIR spectra of HTAW materials; (b) optical microscopy image of a fibre of HTA2/2; and (c) chemical mapping of the area selected in (b) ( $\square$ : agave americana 21 hydrochar (HTA0/4), ㅁ: mimosa tannin hydrochar (HTA4/0), $\mathbf{\square}$ : insignificant component).

22 Figure 9: Effect of $\mathrm{pH}$ and temperature on the adsorption of TC on ac2_CHTA2/2 at 23 equilibrium $\left(C_{0}=10 \mathrm{mg} / \mathrm{L}, m=0.05 \mathrm{~g}, V=100 \mathrm{~mL}\right)$.

24 Figure 10: Nonlinear fit to the kinetics of TC adsorption onto: (a) ac2_CHTA2/2 and F300 25 with PFO and PSO models at $\mathrm{pH} 4,25^{\circ} \mathrm{C}$ and $C_{0}=100 \mathrm{mg} / \mathrm{L}$; and (b) onto ac2_CHTA2/2 26 only with PSO model at different initial concentrations for $\mathrm{pH} 7$ at $25^{\circ} \mathrm{C}$.

27 Figure 13: Adsorption isotherms of TC onto ac2_CHTA2/2, showing the effects of pH and 28 temperature: (a) fit with Langmuir model, and (b) fit with Freundlich model. 